\title{
Experimental Study on Improving the Compressive Strength of UHPC Turntable
}

\author{
Jiawei Wang and Quansheng Sun (iD) \\ School of Civil Engineering, Northeast Forestry University, Harbin 150040, China \\ Correspondence should be addressed to Quansheng Sun; hrbsqs@126.com
}

Received 11 March 2020; Accepted 26 June 2020; Published 18 July 2020

Academic Editor: Antonio Boccaccio

Copyright ( 2020 Jiawei Wang and Quansheng Sun. This is an open access article distributed under the Creative Commons Attribution License, which permits unrestricted use, distribution, and reproduction in any medium, provided the original work is properly cited.

\begin{abstract}
Purpose. In the recent years, horizontal rotation methods have been widely used for bridge construction, particularly for constructing overpass bridges on highways, railways, and shipping. However, bridges constructed using the swivel construction method bear several types of loads during the rotation process. Furthermore, the bridge turntable, which is the core force-bearing component of the structure, bears considerably large vertical pressure and horizontal frictional resistance. The present research proposes three strengthening methods when applying ultrahigh performance concrete (UHPC) materials to the turntable of a spherical hinge to improve structural reliability. Furthermore, the mechanical properties of the structure are evaluated using a unidirectional compressive strength test to provide a theoretical and experimental basis for the application of the UHPC material. Design/Methodology/Approach. To evaluate the mechanical performance of the turntable of a spherical hinge, scale models of six sets of UHPC turntables-steel tube-UHPC, stirrup-UHPC, and directional steel fiber UHPC-were constructed in the study. The compressive strengths of the turntable specimens were calculated after theoretical analysis. After obtaining the load-displacement curves of the cube specimens, the force characteristics of the turntable and the failure mechanism of the structure were analyzed by observing the failure mode of the specimens. Findings. The compressive strength of the steel tube-UHPC turntable was $207 \mathrm{MPa}$, which can completely replace the traditional steel turntable. In addition, the stirrup-UHPC turntable demonstrated a significant loading effect. However, the effect of the restraint radius of the stirrup needs to be considered during the design; otherwise, the loading effect is poor. Furthermore, a directional steel fiber UHPC turntable can improve the compressive strength to a certain extent. We summarize the failure mechanism of the spherical hinge turntable specimens that are expected to play a role in UHPC spherical hinge in engineering applications and construction monitoring. Originality/Value. To the best of our knowledge, this study is the first to employ the UHPC, steel tube-UHPC, stirrup-UHPC, and directional steel fiber spherical hinge turntables in the swivel construction of bridges. The compressive strength and mechanical characteristics of the UHPC structure meet the requirements of the turntable, and more importantly, the manufacturing process (on-site pouring) of the aforementioned UHPC turntable structures is relatively simple. Finally, the manufacturing cost of the turntables is expected to be reduced by more than $50 \%$ compared to those of traditional turntables.
\end{abstract}

\section{Introduction}

A spherical hinge structure is the most important loadbearing component in a swivel bridge structure; it bears the entire load of the bridge superstructure, and thus, it needs to have a relatively high compressive bearing capacity [1-3]. A spherical hinge structure is shown in Figure 1; the spherical hinge turntable structure is a flat cylindrical structure that has two parts: the upper part (convex spherical surface) and the lower part (concave spherical surface). Based on the weight of the bridge, the radius of the structure ranges between $4 \mathrm{~m}$ and $10 \mathrm{~m}$, its height is around $1-2 \mathrm{~m}$, and its height to diameter ratio is less than 0.5 . For rotating construction, the compressive stress of the turntable generally can exceed $50 \mathrm{MPa}$, while the safety coefficient of the turntable is proposed to exceed 2.0 as per the Chinese codes; i.e., the compressive load capacity of the spherical hinge should reach $100 \mathrm{MPa}$. A compressive strength higher than 


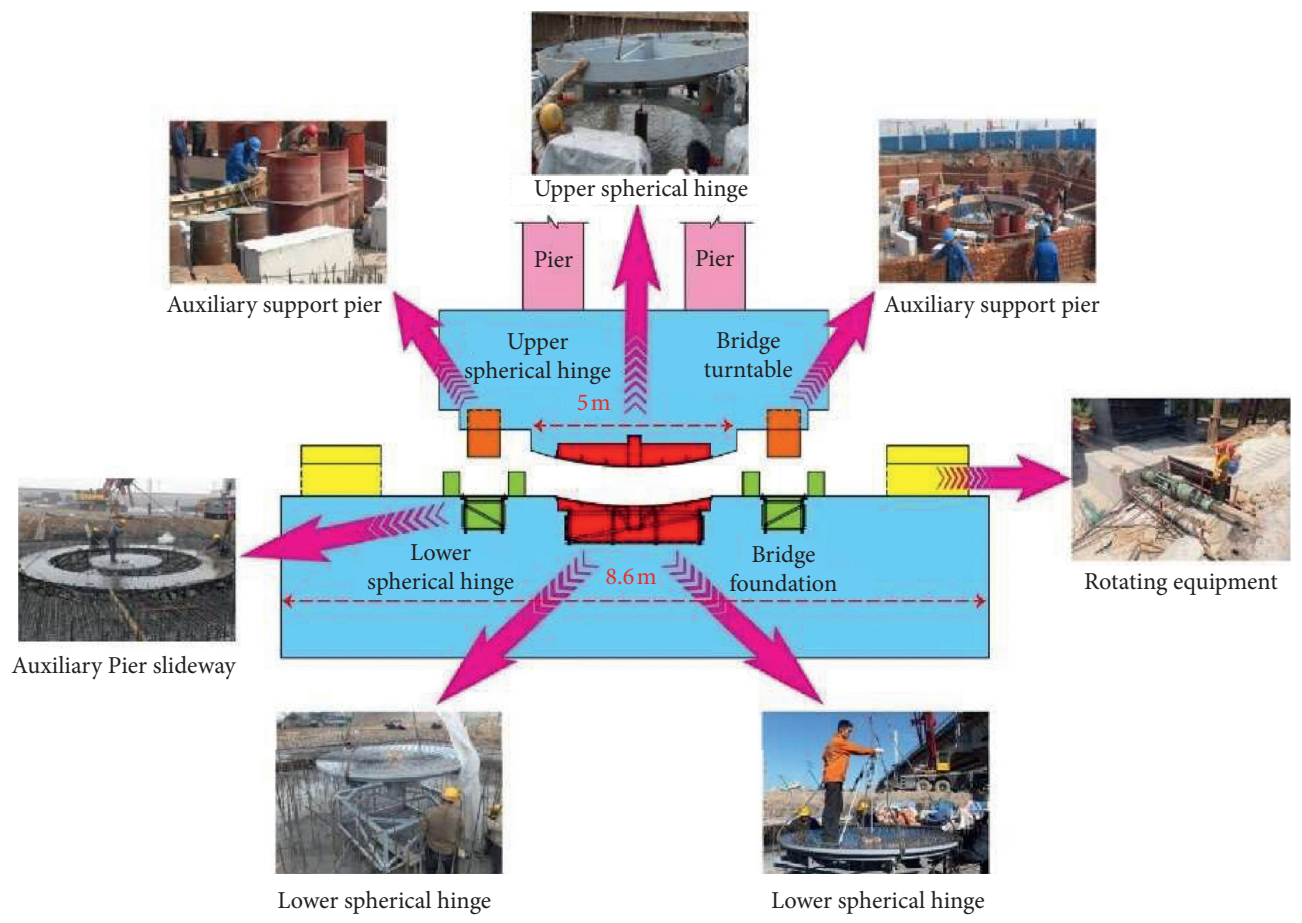

Figure 1: Main structure of a horizontal rotation system.

$150 \mathrm{MPa}$ can be achieved by using ultrahigh performance concrete (UHPC) cubes $[4,5]$. However, the failure mode of the spherical hinge structure and the cubic structure is different; the external surface of the specimen has no restraining effect, and it cannot exert the compressive performance of the core concrete. The compressive strength of these cubes can reach only about $60 \mathrm{MPa}$. To exploit the properties of UHPC materials, it is necessary to impose a certain constraint on the outer surface of the rotating cylinder of the spherical hinge to improve the compressive strength of the UHPC turntable structure.

The compressive strength of the material can be improved to some extent by changing the water-cement ratio, the proportion of each component of the material, and the curing method; however, the effect is negligible [6-8]. Therefore, a method to improve the compressive strength of a cylindrical turntable by imposing external constraints is proposed in this paper. There are three approaches to achieve this: (1) installing a steel sleeve outside the cylindrical spherical hinge test piece, i.e., a steel tube-UHPC combination structure; (2) arranging a stirrup in the spherical hinge specimen; and (3) arranging steel fibers along the circumferential direction, i.e., a method of aligning steel fibers along a certain direction. The experimental results prove that these approaches considerably improve the compressive load carrying capacity of the turntable. The mechanism behind the first method resembles the concept of concrete-filled steel tubes, which originated during the construction of the Steven Bridge in England in the 19th century [9]. At that time, concrete was used to prevent rust on the inner wall of the steel tubes; however, at the end of the 20th century, the mechanical properties of concrete were being studied [10]. When a concrete-filled steel tube structure is subjected to external load, the steel tube demonstrates its high-strength properties and the concrete demonstrates its strong compressive bearing capacity. The concrete in the core area has a certain restraining effect on the steel tube wall, which improves the stability of thinwalled materials. In turn, the steel tube acts as a ferrule on the core concrete, thereby increasing the compressive strength of the concrete [11]. For the second method, stirrups are placed in the specimen to restrain the lateral deformation of the concrete under pressure in the compression zone; this restrains the core concrete and has an anticrack effect on the cracked edges, which improves the UHPC cylinder compressive strength of the turntable. When changing the arrangement of the steel fibers, the current method modifies the UHPC material through the action of an electric field on the steel fibers, thereby improving the tensile properties of the material. For example, Gao [12-17] et al. designed a directional arrangement for a steel fiber device, which considerably improves the flexural strength of the specimen by controlling the flow direction of the concrete. This kind of device can easily and effectively control the arrangement direction of the steel fiber. In this paper, we improve this device: a rotating bladed disk is added inside the equipment to improve the preparation speed of UHPC. Please refer to Figure 2 for details.

In this study, 6 sets of scale models of UHPC (cylindrical, $\varphi 100 \mathrm{~mm}$; height $=50 \mathrm{~mm}$ ) are employed, and the compressive strength and load-displacement curves of three types of UHPC spherical hinge structures-the steel tubeUHPC spherical hinge specimen, stirrup-UHPC spherical hinge specimen, and directional steel fiber UHPC spherical hinge specimen-are evaluated. Furthermore, the reasons for the increased bearing capacity of the spherical hinge 


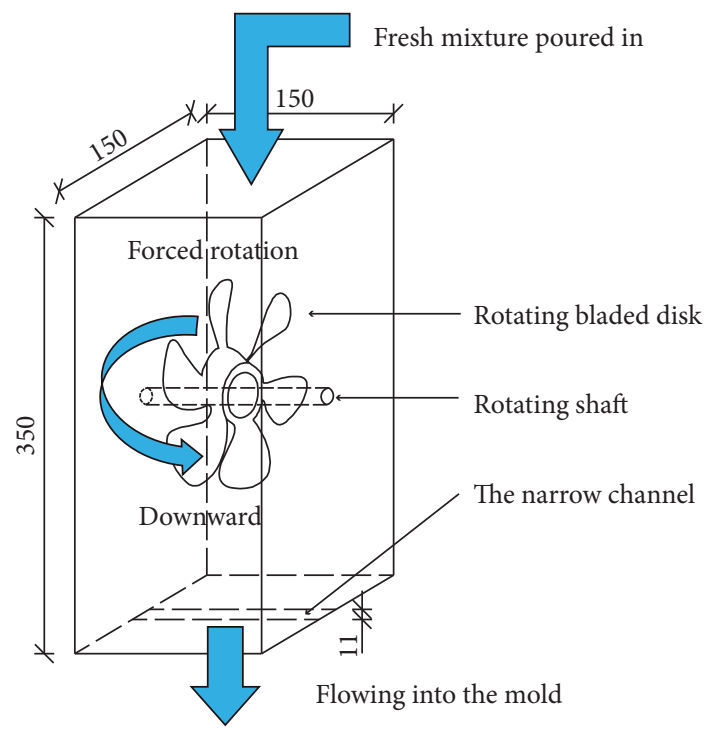

Figure 2: Steel fiber directional arrangement device (unit: mm).

structures are also identified, and several formulas for calculating the compressive strength of the spherical hinge are derived. These formulas are then compared with the test results to verify the accuracy of the theoretical research. The compressive strength of a $10 \times 10 \times 10 \mathrm{~cm}$ cube specimen is often used as the strength index of the bridge structure in engineering. Similarly, this article tries to deduce the compressive strength of the spherical hinge to that of the swivel structure. As to the shape of the spherical hinge, it is generally a two-cylindrical structure (upper and lower spherical hinges). Therefore, in the compression test, the spherical hinge adopts a cylinder with a diameter of $10 \mathrm{~cm}$, and its size is similar to that of the cube.

This paper first introduces the uniaxial compression test of the spherical hinge specimen and evaluates the compressive performance of various types of spherical hinge specimens via the observation of several indexes such as compressive strength, load-displacement curve, and failure mechanism. Then, the calculation formula of the compressive bearing capacity of three types of UHPC spherical hinge structures is derived via theoretical analysis and finite element simulation of the limit state of the spherical hinge specimen. The results show that the error between the experimental value and the theoretical value is small and prove that the research results of this paper would promote the development of the swivel bridge.

\section{Materials and Methods}

2.1. Material Properties. The UHPC specimen is composed of several materials such as ordinary Portland cement, silica fume, fine aggregate, high-efficiency water-reducing agent, and steel fiber. Among them, the cement adopts the Chinese standard GB175-2007, i.e., ordinary Portland cement at $52.5 \mathrm{MPa}$, which maps with ASTM C150 of the American standard [18]. Silica fume is an ultrafine mineral mixture, and its fineness and specific surface area are 80-100 times than that of cement. Silicon powder improves the fineness and activity of the material, reduces the internal defects of the material, and increases the compactness of the structure. The content of $\mathrm{SiO}_{2}$ in the silicon fume is $96 \%$, which conforms with the Chinese regulation GB/T 21236-2007 that matches the American regulation ASTM C1240 [19]. The features and chemical compositions of cement and silica fume are summarized in Table 1.

To increase the density of UHPC materials, only fine aggregates are used in the concrete. The quartz sand used is of 20-70 meshes $(0.425-0.850 \mathrm{~mm})$ and $40-70$ meshes $(0.212-0.425 \mathrm{~mm})$ size. The water-reducing agent is an important material to reduce the water-cement ratio, it has a strong dispersion effect on cement particles, and it can comprehensively improve the properties of concrete. Furthermore, in this study, polycarboxylic acid superplasticizer (bulk density: $610 \mathrm{~kg} / \mathrm{m}^{3}$ ) is used at a dosage of $0.55 \%-0.85 \%$ of the cementitious material; the solid content is $97 \%$, and the water reduction rate is about $30 \%$. The experimental results indicate that the optimal admixture of the waterreducing agent is when the content reaches $0.8 \%$ of the cementing materials. In this case, the stirred UHPC material has better fluidity and less content. The addition of steel fibers increases the ductility of concrete, improves the flexural and crack resistance of concrete, and slightly increases the compressive strength. The steel fibers have a diameter of $0.2 \mathrm{~mm}$, a length of $13 \mathrm{~mm}$, a density of $7.9 \mathrm{~g} /$ $\mathrm{cm}^{3}$, a tensile strength of $2850 \mathrm{MPa}$, and an elastic modulus of $200 \mathrm{GPa}$.

2.2. Mixing Proportion of Specimens. 6 sets of specimens were designed for this study to evaluate the compressive strength of the UHPC spherical hinge and cube pieces in each set. The water-to-gel ratio of all specimens is 0.18 . The 
TABLE 1: Chemical and material properties.

\begin{tabular}{lcc}
\hline Chemical composition (\%) & Cement & Silica fume \\
\hline $\mathrm{SiO}_{2}$ & 66.8 & 92 \\
$\mathrm{CaO}$ & 20.3 & 0.3 \\
$\mathrm{Al}_{2} \mathrm{O}_{3}$ & 5.1 & 0.3 \\
$\mathrm{Fe}_{2} \mathrm{O}_{3}$ & 2.7 & 0.4 \\
$\mathrm{MgO}$ & 3.5 & 2.1 \\
$\mathrm{Na}_{2} \mathrm{O}$ & 0.2 & 1.2 \\
$\mathrm{SO}_{3}$ & 2.2 & 0.4 \\
$\mathrm{~K}_{2} \mathrm{O}$ & 0.8 & 3.3 \\
\hline $\mathrm{Material}$ properties & & \\
Apparent density (g/cm & 3 ) & \\
Blaine SSA (m $/ \mathrm{g})$ & 3.11 & 2.85 \\
Compressive strength (3 days; unit: $\mathrm{MPa})$ & 33.8 & - \\
\hline
\end{tabular}

mass ratio of cement, silica fume, and quartz sand is $1: 0.3$ : 1.1. The first set of specimens is used as the benchmark, and the content of steel fiber is $1.5 \%$. In the second set, the content of steel fiber is changed to $2.5 \%$ to evaluate the effect of specimens on the compressive strength. In the third set, the steel fibers are arranged along the direction of the spherical hinge to detect its effect on the compressive strength of the test piece. In the fourth set, we place a $0.8 \mathrm{~mm}$ thick steel tube outside the cylindrical specimens to evaluate the effect of the restraint of the steel tube on the compressive strength of the specimens. In the fifth and sixth sets, two $6 \mathrm{~mm}$ diameter stirrups are used in the spherical hinge to evaluate the effect of the restraint of the stirrups on the compressive strength of the test pieces. The restraining radii of the two stirrups are $5 \mathrm{~cm}$ and $8 \mathrm{~cm}$, and the vertical spacing of stirrups is $2.5 \mathrm{~cm}$. Furthermore, two sets of $100 \times 100 \times 100 \mathrm{~mm}$ cube specimens are used in this test, and the cube compressive strength data of the UHPC material are obtained.

2.3. Specimen Preparation and Maintenance. Specimens are prepared according to the mix proportions listed in Table 2. An HX-15 concrete mixer (Beijing, China) is used to mix the materials. Three steps are performed to place the materials into the mixer:

(1) The cement and silica fume are added into the mixer, which is then rotated clockwise at a speed of $140 \pm 5 \mathrm{rpm}$, for $2 \mathrm{~min}$; then, quartz sand is added, and mixing is continued for another $2 \mathrm{~min}$.

(2) The steel fiber material is added evenly. As the length of the steel fiber is small and it is agglomerated in the natural state, it has to be sieved using a sieve with a diameter ranging between 5 and $12 \mathrm{~mm}$, and they are mixed while sieving.

(3) The water-reducing agent and water are mixed until an aqueous solution is obtained; this solution is then added into the mixer evenly. Next, the rotation speed is increased to $285 \pm 5 \mathrm{rpm}$, for $6 \mathrm{~min}$; this is followed by a change in the rotation direction. After $5 \mathrm{~min}$, we obtain a homogeneous mixture. In total, it takes $15 \mathrm{~min}$ to mix all the materials.
Diameter of stirrup and restraint diameter of stirrup are shown in Figure 3.

The mixtures are poured into a steel mold shown in Figure 4 . The mixture is poured into the template in two parts, and then, the entire template is placed on a shaking table for $60 \mathrm{~s}$; after that, it is covered with a plastic film for curing. The curing temperature is $24 \pm 3^{\circ} \mathrm{C}$, and the humidity is maintained at $95 \%$. After $24 \mathrm{~h}$, the specimen sets are demolded and side steel tubes are installed on the fourth set of the test pieces.

To evaluate the effect of the direction arrangement of the steel fibers on the compressive strength of the spherical hinge structure, a special set of mechanical equipment was designed for this test. The disordered steel fibers in the specimen were arranged perpendicular to the radius to maximize the structural circumferential constraint and reduce the lateral deformation of the spherical hinge. Currently, magnetic and electric fields are the main methods employed to change the direction of steel fibers to meet the experiment requirements. However, applying them requires relatively high-test equipment, which would add further difficulties in engineering. To overcome this issue, this study modified a steel fiber orientation device constructed, as shown in Figure 2. The device has dimensions of $150 \times 150 \times 350 \mathrm{~mm}$, with the upper part open, and the width of the caging device is set to $11 \mathrm{~mm}$; in the middle, a leaf disc that rotates clockwise is set with a maximum speed of $80 \mathrm{rpm}$. During the material pouring process, the mixtures are poured into the device from the top end and are forced downwards after passing through the leaf disc. When the mixture reaches the bottom of the device, it needs to pass through the limiting device, which restricts the flow of substances above $11 \mathrm{~mm}$. For example, when the particle size of the cementing material is less than $11 \mathrm{~mm}$, it can flow smoothly; however, when the length of the steel fiber is $13 \mathrm{~mm}$, it can only flow out in the direction that is parallel to the flow direction. The steel fiber perpendicular to the flow direction is blocked by the limiting device and needs to be changed to flow out. In this study, the steel fibers are arranged along the direction of the spherical hinge, i.e., in a circular manner, using the designed device. The results show that more than $70 \%$ of the steel fibers can be arranged along the designed direction.

After the mixing, the specimens are placed in a standard curing room for $72 \mathrm{~h}$ and in a steam-curing box; the temperature of the curing box is set to $95^{\circ} \mathrm{C} \mathrm{[17].} \mathrm{We}$ focused on the initial heating rate and the cooling rate to ensure that heating rate is not greater than $15^{\circ} \mathrm{C} / \mathrm{h}$ and the cooling rate is not greater than $12^{\circ} \mathrm{C} / \mathrm{h}$, when performing steam curing. The steam curing time, temperature, and temperature fall and rise speeds are all controlled via computer programs. The steam-curing box is shown in Figure 5, the externally constrained steel pipes and stirrups are shown in Figure 3, and the CFST spherical hinge is shown in Figure 6. Each set of specimens is subjected to a pressure test after one day of steam curing. 
TABLE 2: Mix proportions of UHPC.

\begin{tabular}{lcccccccc}
\hline No. & w/b & $\begin{array}{c}\text { Cement } \\
(\mathrm{g})\end{array}$ & $\begin{array}{c}\text { Silica fume } \\
(\mathrm{g})\end{array}$ & $\begin{array}{c}\text { Coarse sand } \\
(\mathrm{g})\end{array}$ & $\begin{array}{c}\text { Fine sand } \\
(\mathrm{g})\end{array}$ & $\begin{array}{c}\text { Steel fiber } \\
(\%)\end{array}$ & $\begin{array}{c}\text { Water-reducing } \\
\text { agent }(\mathrm{g})\end{array}$ & Enhancement method \\
\hline 1 & 0.18 & 920 & 276 & 202 & 810 & 1.50 & 10.53 & - \\
2 & 0.18 & 920 & 276 & 202 & 810 & 2.50 & 10.53 & Add steel fiber \\
3 & 0.18 & 920 & 276 & 202 & 810 & 1.50 & 10.53 & Directional steel fiber \\
4 & 0.18 & 920 & 276 & 202 & 810 & 1.50 & 10.53 & CFST \\
5 & 0.18 & 920 & 276 & 202 & 810 & 1.50 & 10.53 & With stirrups (diameter at $5 \mathrm{~cm})$ \\
6 & 0.18 & 920 & 276 & 202 & 810 & 1.50 & 10.53 & With stirrups (diameter at $8 \mathrm{~cm})$ \\
\hline
\end{tabular}

w/b: water-binder ratio; CFST: turntable specimen constrained by the steel tube.

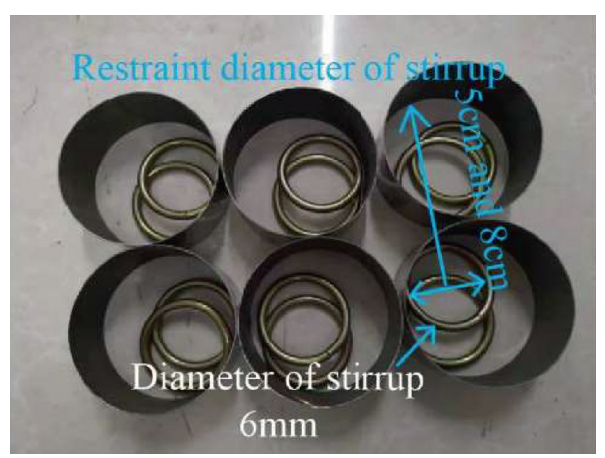

FIgURE 3: Steel pipe and stirrups specimen.

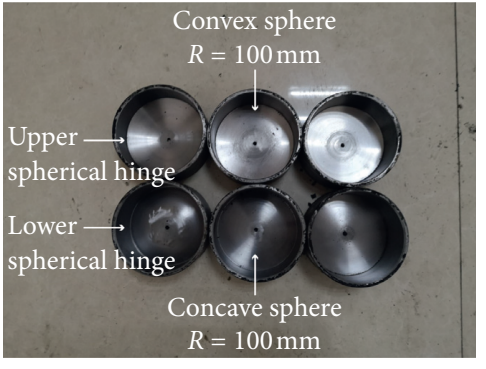

(a)

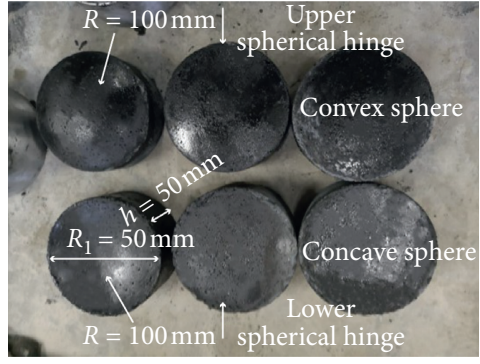

(b)

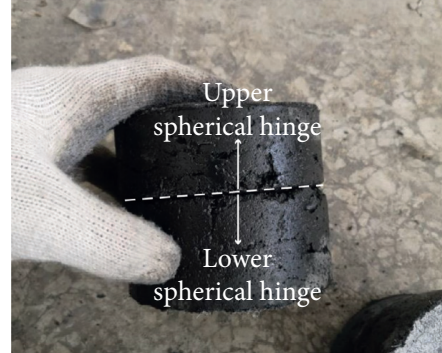

(c)

FIgURE 4: Steel form and spherical hinge specimen.

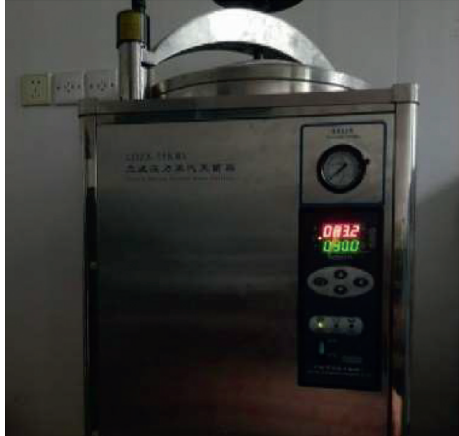

Figure 5: Steam curing box.

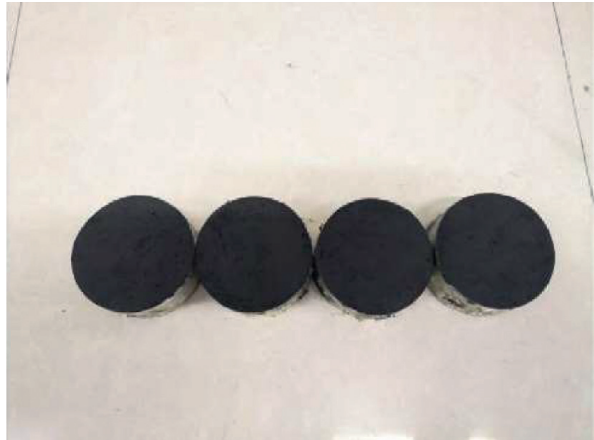

FIgURE 6: UHPC spherical hinge.
2.4. Experiment Method. We performed a compressive strength test after curing the test piece. The loading device was a WAW-2000-type universal testing machine (Jinan
Shijin Company), with a maximum loading capacity of $2000 \mathrm{kN}$, as shown in Figure 7. The loading rate of the cube specimens and the spherical hinge specimens were set at 


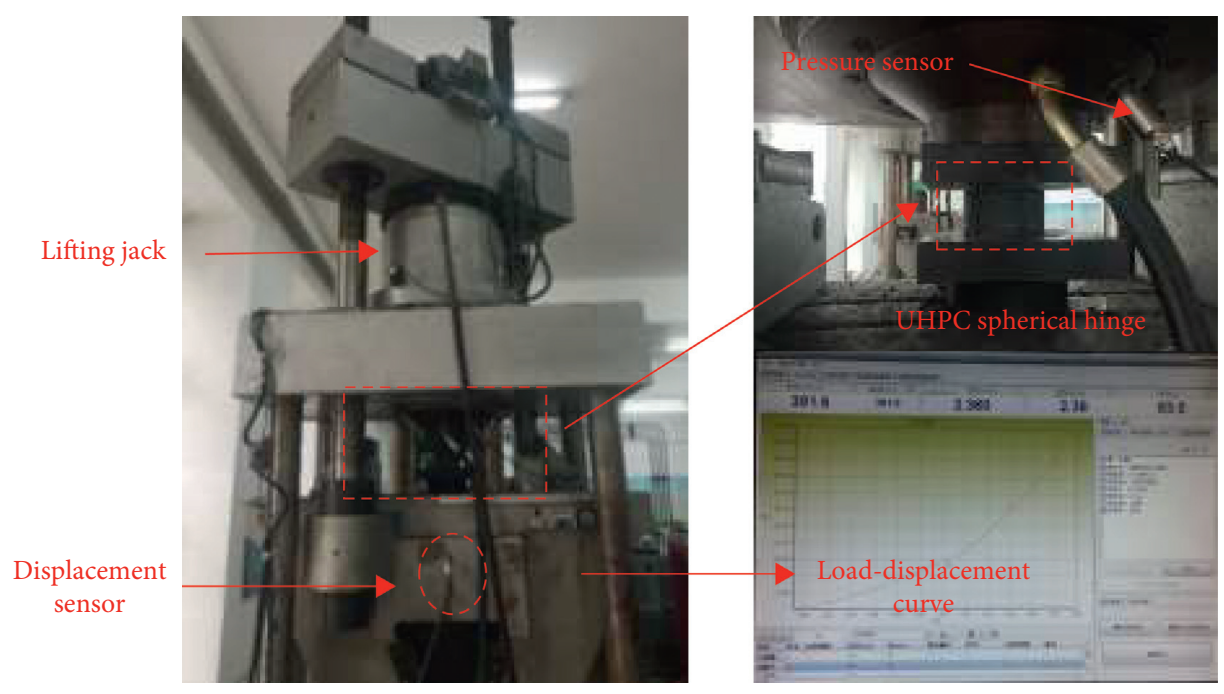

Figure 7: Test loading scheme.

$1 \mathrm{MPa} / \mathrm{s}$; three specimens were included in a set. The standard of the compressive bearing capacity value was as follows: first, determine whether the ratio of the difference between the maximum value and the intermediate value to the intermediate value is greater than 0.15 ; then, decide whether the ratio of the difference between the median and minimum value to the intermediate value is greater than 0.15 . If the ratio of the two is less than 0.15 , then the compressive strength value takes the average of the three data. However, if one of the ratios between the two is greater than 0.15 , then the compressive strength value takes the median of the three data; if both are greater than 0.15 , the results of the set are invalid and need retesting.

The cubic compressive strength $f_{c u}$ is calculated as

$$
f_{\mathrm{cu}}=\frac{F}{A},
$$

where $F$ refers to the failure load of the specimen and $A$ is the bearing area of the specimen. The results show that the compressive strength of the spherical hinge is less than that of the cubes for the same ratio, and the compressive strength of the spherical hinge is $\sim 50 \%$ that of the cube. Based on (1), we propose that the ultimate compressive strength of the spherical hinge can be calculated as

$$
f_{\mathrm{cu}}^{\prime}=k \frac{F}{A} \text {. }
$$

After transformation, we get

$$
f_{\mathrm{cu}}^{\prime}=k f_{\mathrm{cu}},
$$

where $f_{\mathrm{cu}}^{\prime}$ is the ultimate compressive strength of the spherical hinge, while $f_{\mathrm{cu}}$ is the compressive strength of the material cube. The coefficient $k$ represents the shape coefficient of the spherical hinge, which is related to the radius of the spherical hinge $R$ and the radius of the support $R_{1}$. Indeed, (3) links the compressive strength of the cube with the ultimate compressive strength of the spherical hinge. In this case, the most important issue is obtaining the coefficient $k$, which is related to the maximum compressive stress of the spherical hinge under uniaxial compression.

\section{Results and Discussion}

3.1. Cube Compressive Strength. To achieve accurate test results, loading is performed with equal stress and the loading speed is $1 \mathrm{MPa} / \mathrm{s}$. During loading, the steel fiber inside the specimens produces some "pitter-patter" sound. The stress value does not increase considerably until the cube reaches its maximum compressive bearing capacity; however, the displacement increases rapidly. The cube specimen reaches its maximum load with a loud sound, and hence, the test machine stops loading. The compressive strength of each set is shown in Figure 8.

Figure 8 shows that the compressive strength value of the cubic specimen in the test exceeds $148 \mathrm{MPa}$. That is, the set strength of the specimens meets the test requirements. Among the two sets, the average compressive strength of the first set, i.e., specimens 1 to 3 , is $150.3 \mathrm{MPa}$, whereas that of specimens 4 to 6 (second set) is $154.3 \mathrm{MPa}$. With the steel fibers possessing the same specifications, the compressive strength of the cube specimens with $2.5 \%$ content is slightly higher than that of the $1.5 \%$ test specimen, thus increasing by $2.66 \%$. However, when the content of the steel fiber is too high $(2.5 \%)$, the uniformity of the material is relatively poorer when the concrete is mixed, and the steel fiber is easy to knot. The mixing time in the forced mixer is at least $20 \mathrm{~min}$; however, with an increase in mixing time, the compressive oxidation layer on the surface of the steel fiber is damaged, and the fluidity of the concrete when entering the mold is poor. Owing to the abovementioned reasons, it is recommended to use $1.5 \%$ content of the steel fiber in the spherical hinge structures to achieve sufficient compressive strength.

3.2. Load-Displacement Curve of Cube Specimen. The loading process of the cube specimen is shown in Figure 9(a). The 


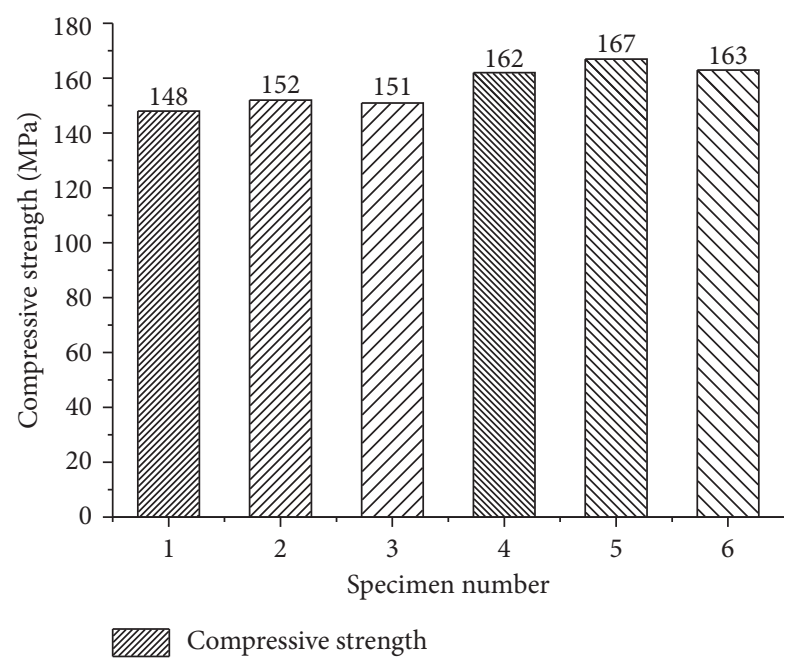

FIGURE 8: Compressive strength of each group of specimens.

top and bottom of the specimen are covered with $20 \mathrm{~cm}$ wide and $4 \mathrm{~cm}$ thick steel plates; they are considered as fixtures for uniform loading. The loading process adopts equal-rate stress control, and the loading rate is $1 \mathrm{MPa} / \mathrm{s}$. The stressdisplacement curve of the cubic specimen under two types of steel fiber content is shown in Figure 9(b).

In Figure 9(b), 13-1.5 refers to the test pieces in the first group, with $1.5 \%$ of $13 \mathrm{~mm}$ long steel fibers; similarly, 13-2.5 refers to the test pieces in the second group, with $2.5 \%$ of $13 \mathrm{~mm}$ long steel fibers.

Based on Figure 9(b), we conclude that the load-displacement curve can be divided into four stages: initial loading stage, elastic deformation stage, plastic deformation stage, and failure stage. The detailed discussion about each phase is provided as follows:

(1) Initial loading stage: in this stage, the curve gradually rises, and each part of the structure begins to receive the force; the slope of the curve of the specimen with a high content $(2.5 \%)$ is higher than that of the specimen with low content $(1.5 \%)$. The curve slope reflects the ability of the structure to resist deformation. Thus, the higher the steel fiber content, the earlier it reaches the elastic deformation stage.

(2) Elastic deformation stage: in this stage, the slope of the curve remains unchanged; here, the structure is in the elastic deformation stage and the steel fiber and concrete in the structure are uniformly stressed. Furthermore, the "pitter-patter" sound of the steel fiber accompanies the loading process. In this stage, the higher the fiber content, the longer the deformation range of the elastic stage, and subsequently, the wider the elastic range of the test piece. Therefore, it can be concluded that the elastic deformation stage is related to the content of steel fibers.

(3) Plastic deformation stage: in this stage, the slope of the curve gradually decreases, and the structure is in the plastic deformation stage, where the structure is about to fail. The higher the steel fiber content, the shorter the plastic deformation stage.
(4) Failure stage: in this phase, the curve suddenly drops, and the loading machine stops loading; thus, the structure is crushed following a tremendous noise.

3.3. Compressive Strength of Turntable. Compressive tests are performed on six sets of spherical hinge specimens, and the compressive strength is then averaged. The test machine is loaded based on the principle of equal stress loading with a loading speed of $1 \mathrm{MPa} / \mathrm{s}$. The load decreases rapidly when it reaches its maximum value, and the structure stops loading after a considerable displacement. The compressive strength of each set of specimens is shown in Figure 10.

Figure 10 shows that the compressive strength of the turntable exceeds $70 \mathrm{MPa}$. However, the compressive strengths of spherical hinge specimens 1, 2, and 5 are far less than that of the cube specimens. Thus, it cannot considerably improve the performance of the material. The following conclusions can be obtained based on the results in Figure 10:

(1) The average compressive strength of the first set of specimens is $72 \mathrm{MPa}$, and that of the second set of specimens is $83 \mathrm{MPa}$. The compressive strength of the turntable increases with an increase in the content of steel fiber. The structure with $2.5 \%$ of steel fibers has a $14.8 \%$ higher compressive strength than that with the $1.5 \%$ structure. Besides, the increase in the content of the steel fiber can increase the number of steel fibers inside the crack-resistant edge. Under uniaxial compression, the edge of the spherical hinge cracks vertically. The increased steel fiber increases the crack resistance of the specimens to a certain extent, and hence, it increases the compressive strength of the specimens.

(2) Steel fibers in the third set are arranged evenly along the direction of the spherical hinge, i.e., in circular manner. In addition, the average compressive strength of the test piece reaches $119 \mathrm{MPa}$. In fact, its compressive strength has been improved greatly; compared with the randomly arranged steel fiber 


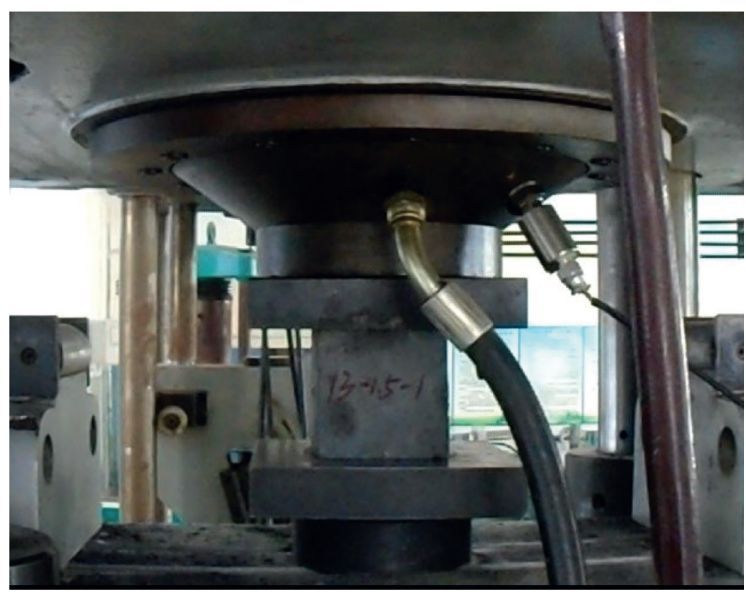

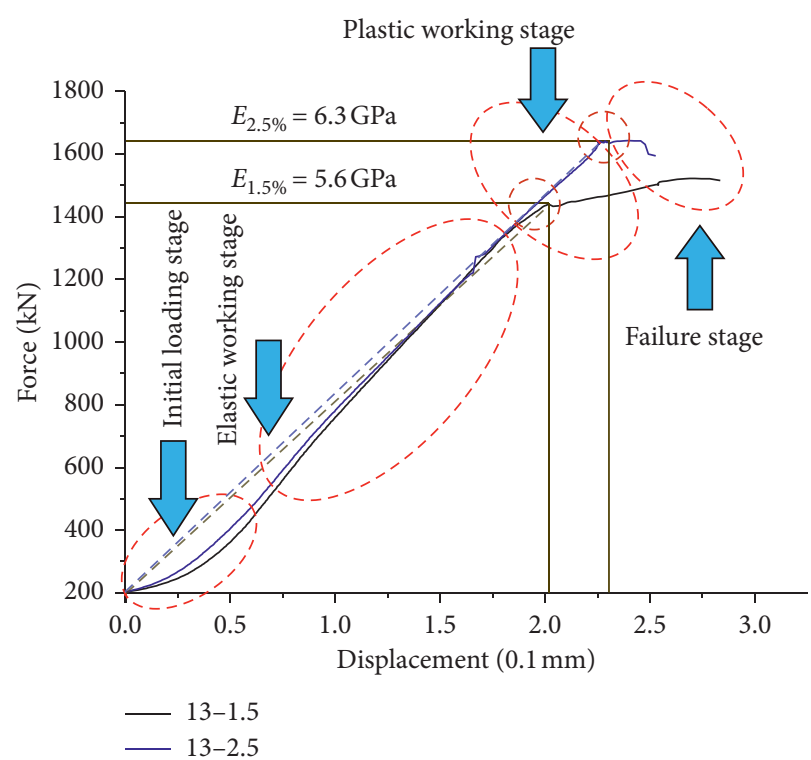

(b)

Figure 9: (a) Loading process of cube specimen; (b) load-displacement curve of specimens with $1.5 \%$ and $2.5 \%$ steel fibers.

spherical hinge specimens, its resistance compressive strength increases by $65 \%$. The steel fibers are arranged along the circumferential direction of the spherical hinge, and the cracking occurs as a vertical crack generated at the edge of the spherical hinge. Most steel fibers are perpendicular to the cracking direction, which delays the time of cracking and improves the compressive strength of the specimen.

(3) The fourth set contains CFST spherical hinge specimens, and the average compressive strength of the specimens is $207 \mathrm{MPa}$. With an increase of $186.3 \%$, it exceeds the cubic compressive strength by $38 \%$. The steel tube acts on the outer side of the spherical hinge, which is equivalent to adding an external restraint to the spherical hinge specimen; the core concrete is thus in a constrained state. The steel tube is under tension, and it does not reach the breaking load until the steel tube reaches the yield state or the core concrete reaches the maximum compressive stress state after being restrained. Eventually, the structure breaks.

(4) Finally, the fifth set includes stirrup specimens, with the diameter of the stirrups at $5 \mathrm{~cm}$. The average compressive strength of the specimens is $78 \mathrm{MPa}$, and its compressive strength increases by $7.9 \%$. The diameter in the sixth set is $8 \mathrm{~cm}$, and the average compressive strength of the specimens is $137 \mathrm{MPa}$; the compressive strength is increased by $90.3 \%$.

From the above points, it can be concluded that when the diameter of the stirrup is small, the area where the core concrete is constrained is small as well; hence, it is unable to restrain the most unfavorable section. When the diameter of the stirrup is increased near the cracking edge, the restrained area increases accordingly, which greatly improves the compressive strength of the specimen.
3.4. Load-Displacement Curve. During the loading process of the spherical hinge specimen, the stress states at different stages are studied. The load-displacement curve of the spherical hinge specimens is shown in Figure 11.

The following conclusions can be drawn from Figure 11:

(1) The load-displacement curve can be divided into elastic deformation, plastic deformation, and failure stages. In the elastic working stage, the curve keeps rising; the steel fiber and concrete in the structure are uniformly stressed, and the steel fiber generates the "pitter-patter" sound during the loading process. When the load reaches a certain value, the load value does not change considerably; however, the displacement value increases rapidly. This is when the structure enters the plastic working stage. On increasing the external load further, the spherical hinge structure enters the failure stage.

(2) Among the 6 sets of specimens, specimens from the 4 and 6 sets show the typical three-stage characteristics, with the plastic deformation stage being relatively more obvious, which indicates the influence of external constraints on the compressive strength of the specimens. The $1,2,3$, and 5 sets consist of two phases: the elastic deformation phase and the failure phase. As the external constraints are small, the plastic deformation stage is thus not obvious.

(3) The maximum values and trends of the curves for the 1,2 , and 5 sets are close. The compressive strength and stiffness of the structure are both small, which indicates that an increase in the compressive strength and stiffness of the specimens caused by increasing the content of steel fibers is very limited. Although a $5 \mathrm{~cm}$ diameter circular stirrup is used for specimen 5 , the range of the stirrup is still small, and hence, the compressive strength and structural deformation 


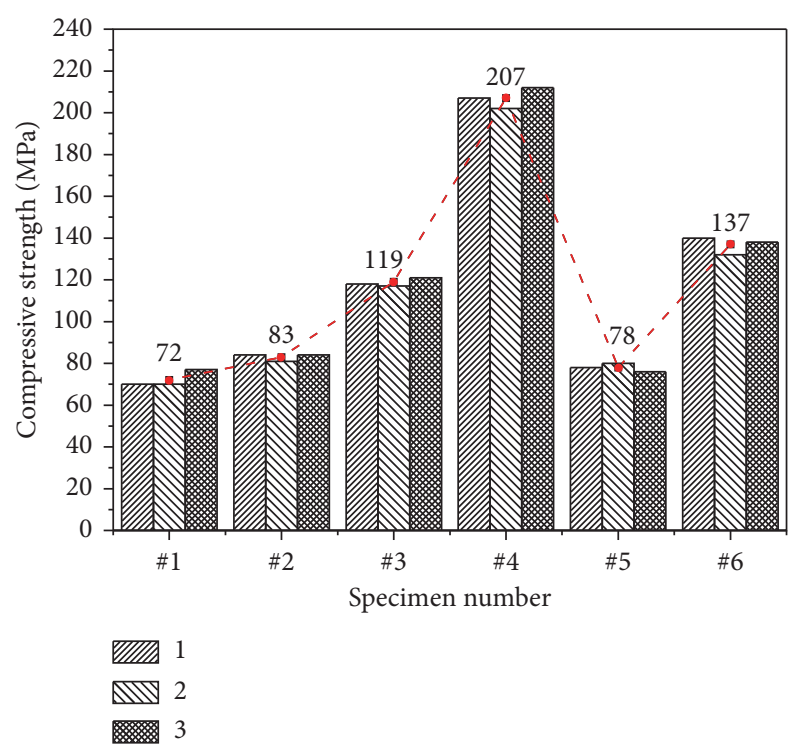

FIgURE 10: Compressive strength of spherical hinge of each set. The red-dotted line in the figure represents the average compressive strength of each set of specimens.

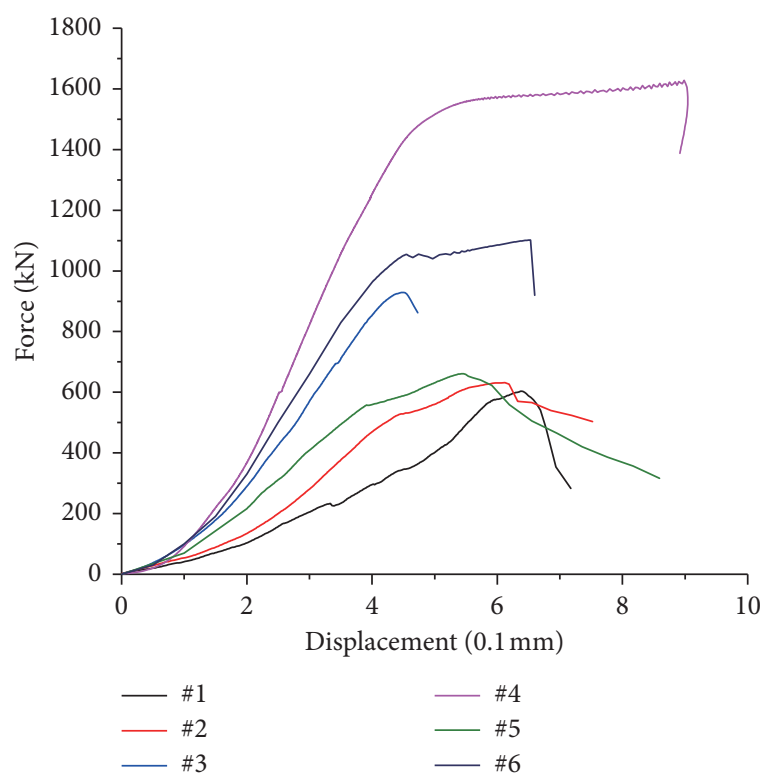

FIGURE 11: Load-displacement curve of turntable specimens (directional arrangement, concrete-filled steel tube, and stirrup setting).

resistance of the specimen are not significantly improved. However, the time of the failure stage increases, which indicates when the restraint radius of the stirrup is small, the specimen is transformed from brittle failure to ductile failure, although the compressive bearing capacity does not increase considerably.

(4) The directional steel fiber specimen has a significantly improved resistance to deformation for specimen 3, which shows when the steel fibers are perpendicular to the radial direction, it can effectively constrain the core concrete and improve the compressive bearing capacity of the turntable specimens. However, the damage stage is very short, and it is sudden brittle damage. The orientation of the steel fibers does not change the ability of the material to resist deformation.

(5) The load-displacement curve of the specimen 6 takes the form of a broken line: the initial curve has a large slope, and the structure has the strongest resistance to deformation at the beginning. After reaching a certain strength, it exhibits another slope; the strength rises slowly, while the deformation increases rapidly. At this stage, yielding occurs at the two stirrups. When the specimen reaches its maximum compressive strength, the stirrups break. Simultaneously, the outer surface of the specimen cracks rapidly along the fracture position of the stirrup, the structural deformation increases further, and the structure fails. Stirrups set with a diameter of $8 \mathrm{~cm}$ can better restrain the core concrete, and the concrete is in a three-way compression state; the structural bearing capacity and resistance to deformation are greatly improved, and the compressive strength is above $124 \mathrm{MPa}$. However, because the stirrups are arranged in a dispersed manner in the concrete, their restraining force on the concrete is not as good as that of steel tubes.

(6) Finally, the CFST method is adopted for specimen 4. There is an obvious increase in its resistance to deformation and compressive strength, and the compressive strength reaches $207 \mathrm{MPa}$ or higher. The load-displacement curve indicates that the slope of the initial section increases gradually, and it quickly passes specimen 6 after the initial deformation reaches $0.1 \mathrm{~mm}$, thus indicating that deformation resistance of the CFST increases with cumulative deformation. When it reaches about $190 \mathrm{MPa}$, the outer steel sleeve generates a yielding. Then, both the slope of the curve slows down and the deformation increases rapidly, while the compressive strength increases slowly. When the outer steel tube reaches the breaking load, the specimens make a loud noise, and the steel plate breaks along the height of the specimen. Here, the compressive strength of the specimen reaches the maximum value, the concrete of the specimen cracks rapidly along the fracture surface of the steel tube, and the specimen is destroyed subsequently. The concrete of the specimen cracks rapidly along the fracture surface of the steel tube, and the specimen is destroyed.

3.5. Failure Mechanism of the Turntable. The basic form of the failure of the spherical hinge specimen is the vertical crack generated along the outer surface of the structure, and the UHPC concrete is pulled and destroyed. As for the steel tube-UHPC and stirrup-restricted UHPC specimens, they have a strong restraint on the outer surface of the specimen, 
which acts on the specimen effectively when the shear peeling failure is about to occur. The external constraints bear the continued loading of external loads, and the structure exceeds the elastic working stage; furthermore, the compressive bearing capacity of the structure is considerably improved. When the vertical load continues to increase, the structure undergoes axial compression; then, the structure undergoes lateral expansion, and the external steel tube and stirrups on the inner side of the specimen generate lateral tensile stress. When the tensile stress exceeds the resistance bearing capacity of the steel plate and tensile bearing capacity of the steel bar, the structure is suddenly damaged. The failure mode at this time is different from that in the UHPC spherical hinge: the steel plate cracks in the vertical direction, and the UHPC specimens on the cracked side quickly results in vertical penetrating cracks; the structure quickly reaches the maximum compressive load capacity and is then damaged subsequently. After the steel bar of the stirrup-UHPC turntable specimen is damaged, a vertical crack quickly occurs, and the structure is damaged.

Directional steel fiber specimens have a weaker lateral restraint than the former two, and their failure modes are between the two. Several cracks are generated along the vertical direction close to $90^{\circ}$. The failure modes of the spherical hinge are shown in Figure 12.

The first and second sets of specimens are UHPC specimens with randomly arranged steel fibers. The failure mode shown in Figure 12 indicates that the structure is relatively complete when the structure is broken, and the core area covers the entire spherical hinge. Therefore, the damage load of the structure is low. As there are no obvious constraints, the structure is thus under unidirectional compression. Several vertical penetrating cracks comprise the surrounding cracking area, and the concrete around the spherical hinge disperses to the surrounding. Structural failure occurs slowly, and there are no obvious signs of failure. The highest point of the failure load is the highest point in the load-displacement curve.

Compared with the first set of specimens, the second set has a larger content of steel fibers and a slightly higher compressive bearing capacity. From the perspective of the failure mode, the number of cracks is reduced slightly, and the increase in the content of steel fibers improves the crack resistance of the component to a certain extent.

The failure pattern for the third set of specimens is shown in Figure 13. There is a slight increase in the cracked area, while the core area is reduced when the structure is damaged. Radial restraints are applied around the specimen, and the structure is under unidirectional compression. A number of vertical cracks compose the surrounding cracking area. When four cracks develop into the core area, the structure is damaged, and the cracks begin to widen. Structural damage occurs quickly, with obvious signs of failure, and a loud noise follows the occurrence of the damage load, and the pressure-testing machine stops loading subsequently.

Compared with the first and second sets of specimens, the third set exerted a certain restraining effect on the structure by aligning the steel fibers to a direction perpendicular to the crack. At this time, the suppression of cracks by the steel fiber reaches the maximum effect. When the load is further increased, the compressive strength of the component is entirely borne by the bonding force between the steel fiber and concrete. When the external load exceeds the bonding force, the structure is damaged and the compressive bearing capacity of the specimen improves significantly. The failure mode is reflected by the decrease in the number of cracks.

The failure pattern of the fourth set is shown in Figure 14. As shown in the figure, when the structure is broken, there is only a wide vertical crack and the core area is the same as the specimen area. A strong radial restraint is applied around the specimen, and the structure is under a unidirectional compression condition. When the structure is about to crack, the outer steel tube starts to bear the external load; the structure then begins to deform laterally under the vertical load. The steel plate resists radial tensile stress; it breaks the moment the tensile stress exceeds the limit, and the structure is subsequently damaged. This occurs quickly with obvious failure signs and a loud noise. Subsequently, the pressure-testing machine stops loading.

Compared with the specimens in the third set, those in the fourth set show a stronger restraining effect on the structure, and the tensile strength of the steel plate resists the structural cracks. Thus, the compressive bearing capacity of the specimen is significantly improved. The failure mode is reflected by a large vertical and horizontal deformation, with the maximum vertical deformation reaching $7 \mathrm{~mm}$. The increase in restraining property of the steel tube improves the plastic deformation ability of the specimens, which improves the compressive strength of the specimens to a certain extent.

The failure pattern for the sixth set is shown in Figure 15. The figure indicates that when the structure is broken, cracking occurs in the area outside the restraint of the stirrups. The cracked part extends along the fracture surface of the stirrup to the core area of the concrete. The specimen exerts a strong radial restraint within the restraint range, and the structure is under unidirectional compression. When the structure is about to crack, the internal stirrups begin to bear the external load; the structure then begins to deform laterally under the vertical load. The stirrup restrains the radial tensile stress. The stirrup breaks when tensile stress exceeds the limit, and the structure is thus damaged. This occurs quickly with obvious failure signs.

In the fifth set of specimens, the restraint diameter of the stirrup was changed to $5 \mathrm{~cm}$. The results showed that the failure mode is the same as that of first and second sets, with its compressive bearing capacity improvement being small. This can be attributed to the restraint range of the stirrup in the core area of the original specimen, rather than the outer cracking area. Therefore, when the component fails, the stirrup does not break, and it plays no effective role.

Compared with the third set of specimens, the sixth set has a stronger restraining effect on the structure, and the tensile strength of the steel plate inhibits the development of the cracks. Thus, the compressive bearing capacity of the 

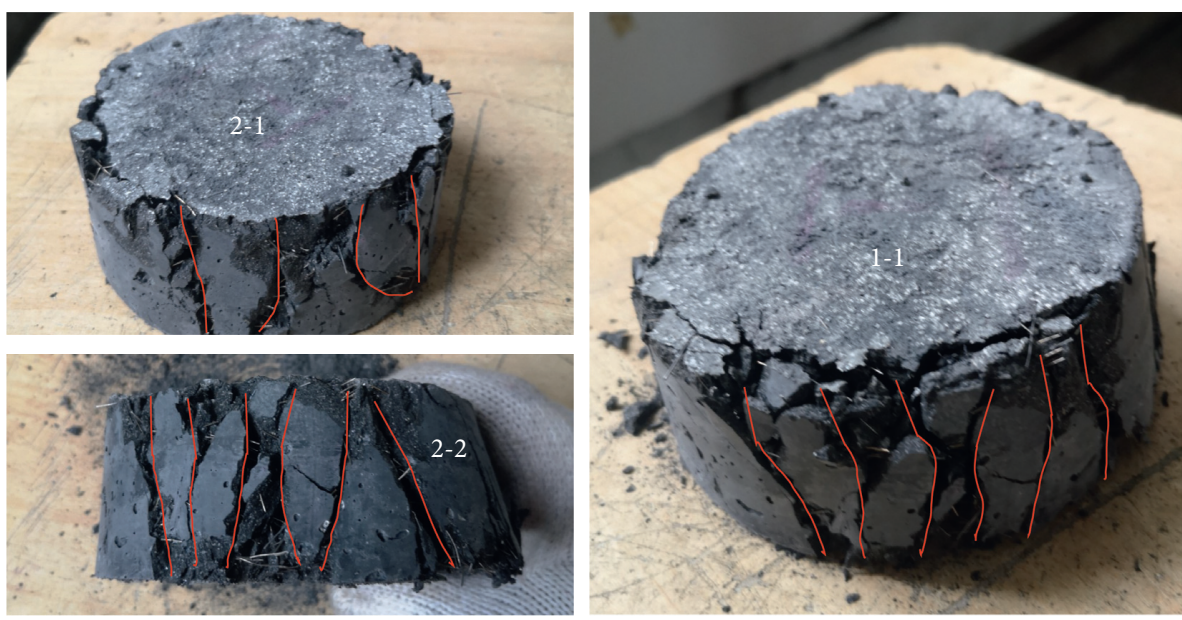

Figure 12: Failure modes of the first and second sets of turntable specimens.
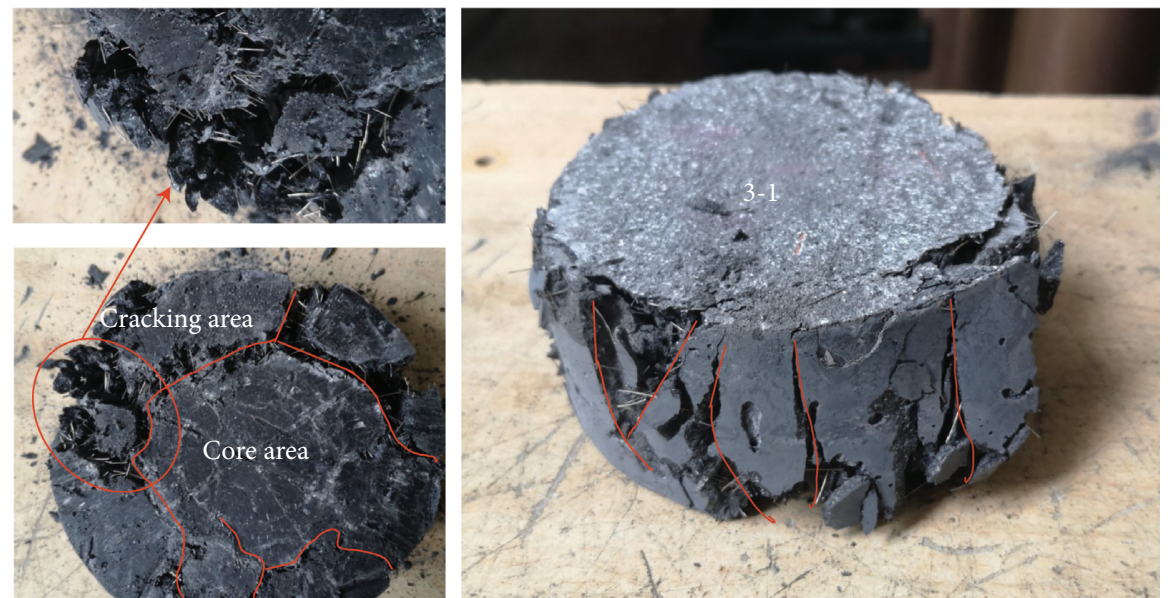

FIgURE 13: Failure modes of the third set of turntable specimens.
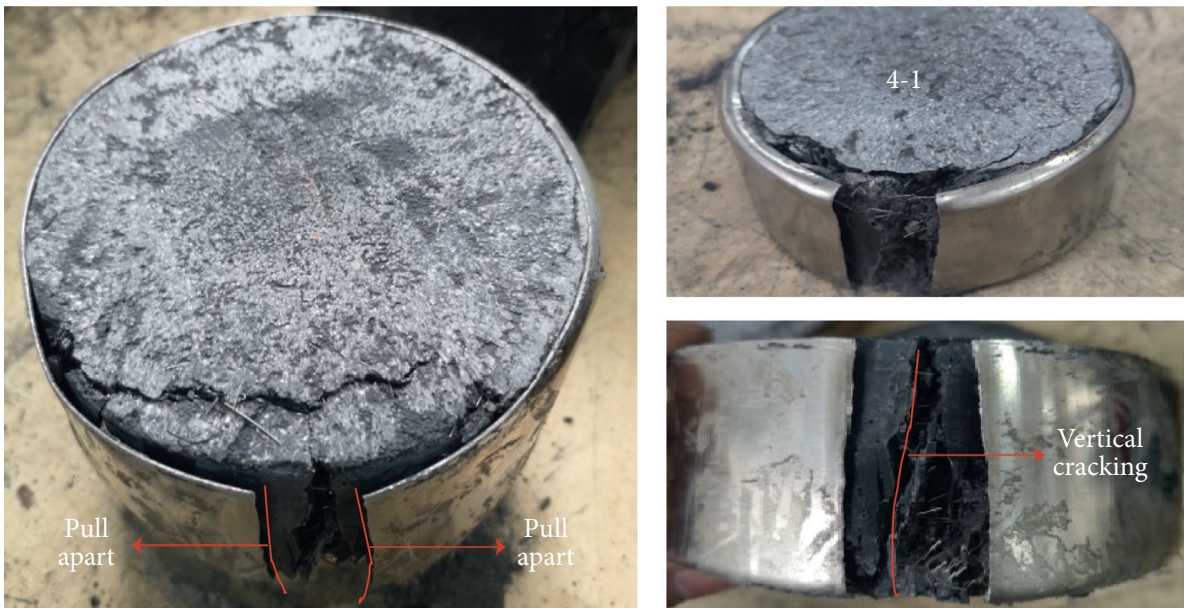

FIGURE 14: Failure mode of the fourth set of turntable specimen. 

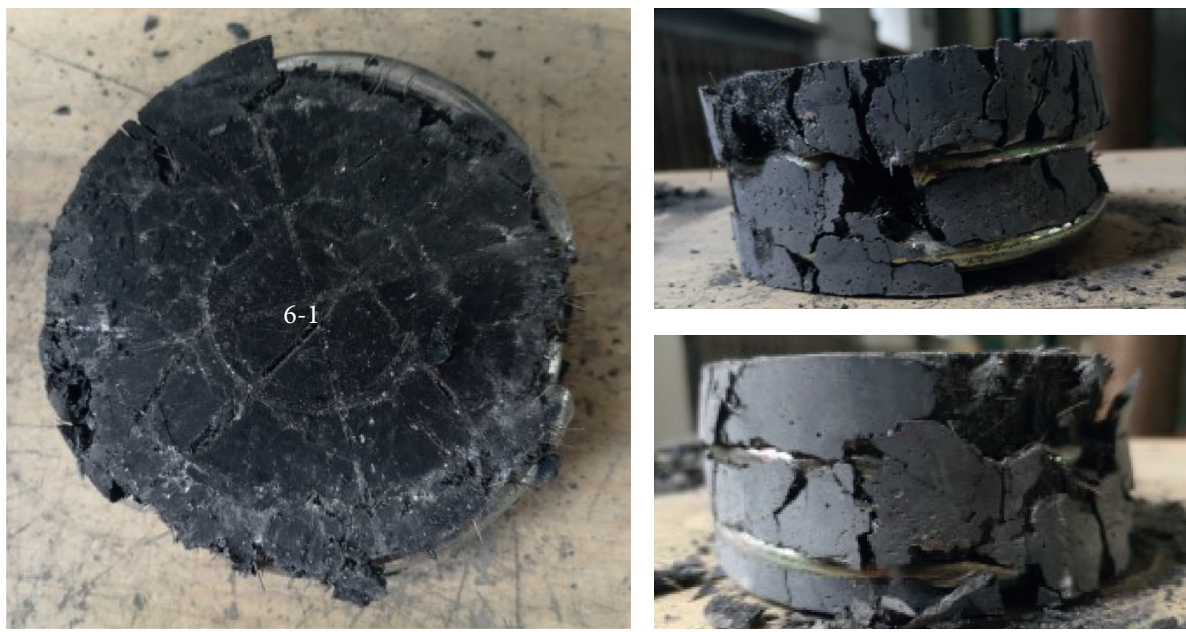

Figure 15: Failure mode of the sixth set of turntable specimen.

specimens is significantly improved. The failure mode is reflected by the specimen experiencing large vertical and lateral deformation, with the maximum vertical deformation reaching $5 \mathrm{~mm}$. An increase in the restraining property of stirrups can improve the plastic deformation ability of the specimen, and it is only weaker than the CFST specimen in terms of the loading effect.

\subsection{Ultimate Bearing Capacity of Spherical Hinge Specimens}

3.6.1. Radial Compression Stress of Spherical Hinge. The value of compressive stress at various points along the radial direction of the spherical hinge is related to the radius of the spherical hinge and the material properties. The calculation model for the radial compressive stress at any point on the spherical hinge is shown in Figure 16.

Assuming that the upper and lower spherical hinges are in close contact and the reaction force $f$ of the lower spherical hinge support is evenly distributed, the radial stress is

$$
\sigma=f(R, F, \alpha) \times \cos \theta
$$

where $\sigma$ refers to the radial compressive stress of the hinge, $R$ is the radius of the spherical hinge, $R_{1}$ is the horizontal support radius of the spherical hinge, and $\alpha$ is the center angle of a certain point on the spherical surface.

$$
F=\int_{0}^{2 \pi} \int_{0}^{\alpha} R^{2} \sin \theta\left(f \cos ^{2} \theta\right) \mathrm{d} \theta \mathrm{d} \alpha \int_{0}^{2 \pi} \frac{f R^{2}}{3}\left(1-\cos ^{3} \alpha\right) \mathrm{d} \alpha=\frac{f \pi R^{2}}{3}\left(1-\cos ^{3} \alpha\right)
$$

From (5), we get

$$
\begin{aligned}
& f=\frac{3 F}{\pi R^{2}\left(1-\cos ^{3} \alpha\right)}, \\
& \sigma=\frac{3 F \cos \theta}{\pi R^{2}\left(1-\cos ^{3} \alpha\right)}=\frac{3 F \cos \theta}{\pi R^{2}\left[1-\left(\left(R^{2}-R_{1}^{2}\right)^{3 / 2} / R^{3}\right)\right]} .
\end{aligned}
$$

\subsubsection{Ultimate Bearing Capacity}

(1) Spherical Hinge. Through (4)-(7), the stress state of the spherical hinge structure under uniaxial compression can be obtained. The calculation formula of the compression bearing capacity of the spherical hinge is derived based on the above conclusions.

According to (7), when $\theta=0$, the radial compressive stress $\sigma$ takes the maximum value; then, the formula is

$$
\sigma_{\max }=\frac{3 F}{\pi R^{2}\left[1-\left(\left(R^{2}-R_{1}^{2}\right)^{3 / 2} / R^{3}\right)\right]},
$$

where $\sigma_{\max }$ is the maximum radial compressive stress of the spherical hinge. Based on the material test, the compressive strength of the cube under the same ratio is considered as $\sigma_{\max }$, i.e., $\sigma_{\max }=f_{\mathrm{cu}}$. The maximum pressure $F_{\max }$ can be obtained by using $R$ and $R_{1}$ into (8). The average compressive strength $f_{\mathrm{cu}}^{\prime}$ of the spherical hinge can be obtained as

$$
f_{\mathrm{cu}}^{\prime}=\frac{F_{\max }}{\pi R_{1}^{2}}
$$

The average compressive strength $f_{\mathrm{cu}}^{\prime}$ of the first and second sets can be then be obtained based on (8) and (9), as summarized in Table 3.

Table 3 indicates that the theoretical results obtained using the calculation formula of the compressive strength of the spherical hinge are in good agreement with the measured data, with the maximum error at $8 \%$; this implies that the formula fits correctly. In the design of the UHPC spherical hinge, the ultimate compressive strength of the spherical hinge is determined by three parameters of the UHPC 


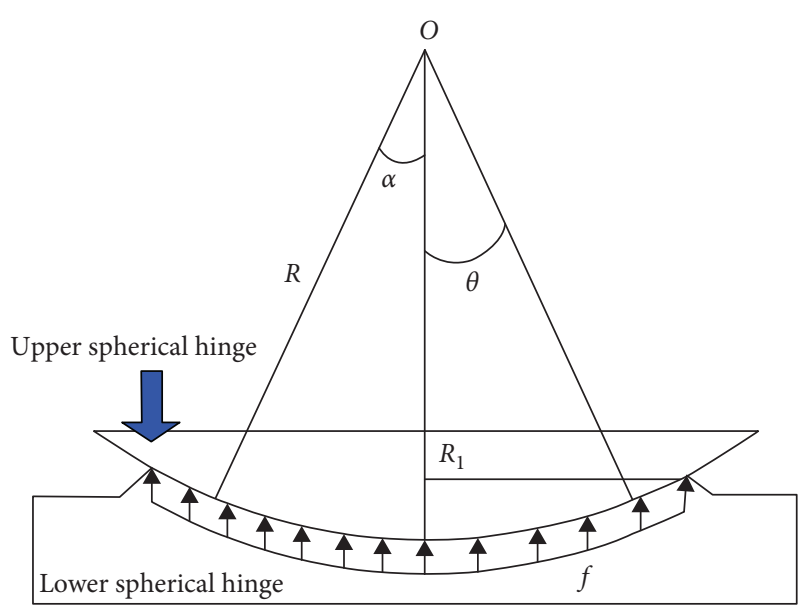

FIGURE 16: Stress distribution of spherical hinge.

material: compressive strength, ball hinge radius, and support radius.

Table 3 indicates that the average compressive strength $f_{\mathrm{cu}}^{\prime}$ of the spherical hinge is $\sim 0.47$ times the radial maximum stress $\sigma_{\max }$; i.e., the coefficient $k$ is 0.47 , and the average compressive strength of the spherical hinge is $47 \%$ of the cubic compressive strength. The compressive strength of the spherical hinge depends on the maximum radial compressive stress at the center of the ball. When the radius of the spherical hinge is $100 \mathrm{~mm}$, the radial maximum compressive stress is 2.1 times the average compressive stress. The internal compressive stress distribution of the cubic specimen is uniform; thus, the compressive strength of the spherical hinge is much smaller than that of the cube.

(2) Steel Tube Constrained Spherical Hinge. The steel tube constrained UHPC turntable test piece is similar to a concrete-filled steel tube structure, which can greatly improve the bearing capacity of the structure: on the one hand, the steel tube provides a restraining effect on the core concrete; on the other hand, the pressure at the top of the test piece is transmitted from the core concrete to the external steel tube using shear stress in the concrete tube, and the steel tube bears some internal load. The strength of the component section is improved accordingly, and the buckling of the steel tube is delayed; however, the use of high-strength concrete will increase the brittleness of the concrete-filled steel tube column. The main influencing factors that affect the compressive bearing capacity and deformation capacity of concrete-filled steel tubular turntables are confinement index, loading method, and specimen height.

The internal force of the structure is analyzed to investigate the working mechanism of the test piece. Furthermore, it is assumed that the steel tube and the core concrete are two parts during the stress process of the structure, which are separately decomposed and calculated during stress calculation. The structure of the steel tube constrained UHPC turntable is shown in Figure 17

When calculating the compressive bearing capacity of steel tube restrained specimens and stirrup restrained
TABLE 3: Theoretical and measured values of compressive strength of spherical hinge.

\begin{tabular}{|c|c|c|c|}
\hline Specimen number & $\begin{array}{l}\text { Measured } \\
\text { values } \\
(\mathrm{MPa})\end{array}$ & $\begin{array}{l}\text { Theoretical } \\
\text { values, } f_{\mathrm{cu}}^{\prime} \\
(\mathrm{MPa})\end{array}$ & $\begin{array}{l}\text { Theoretical } \\
\text { values/ } \\
\text { measured } \\
\text { values }\end{array}$ \\
\hline
\end{tabular}

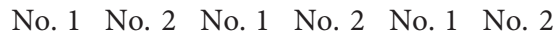

\begin{tabular}{|c|c|c|c|c|c|c|c|}
\hline \multicolumn{2}{|c|}{$\begin{array}{l}\text { Cube compressive } \\
\text { strength }\left(f_{\mathrm{cu}}\right)\end{array}$} & 150 & 164 & - & - & - & - \\
\hline \multirow{3}{*}{$\begin{array}{l}\text { Spherical } \\
\text { hinge }\end{array}$} & First set & 77 & 84 & 70 & 77 & 0.91 & 0.92 \\
\hline & $\begin{array}{l}\text { Second } \\
\text { set }\end{array}$ & 70 & 84 & 70 & 77 & 1.00 & 0.92 \\
\hline & Third set & 70 & 81 & 70 & 77 & 1.00 & 0.95 \\
\hline
\end{tabular}

specimens, we adopt the ultimate analysis method, i.e., the method of obtaining the compressive bearing capacity through the equilibrium conditions of the specimen under the ultimate state of compression. In the calculation, the failure type in the ultimate state of the structure is strength failure, which occurs before stability failure.

The core concrete of the confining components is in a three-way compression state, which greatly improves the strength of the material. The compressive bearing capacity of concrete-filled steel tube is given as follows [20]:

$$
f_{c}^{\Rightarrow}=f_{c}\left[1+1.5 \sqrt{\frac{P}{f_{c}}}+2 \frac{P}{f_{c}}\right],
$$

where $P$ is the lateral pressure of the concrete, $f_{c}$ is the compressive strength of the concrete without lateral pressure, and $f_{\mathrm{c}}^{\Rightarrow}$ refers to the compressive strength of the concrete-filled steel tube. It is assumed that the steel-free fiber concrete is similar to UHPC concrete, and therefore, the same formula can be applied to calculate its bearing capacity. However, they both involve different parameters, and the two expressions are considered to be same, albeit with different parameters. The compressive strength can be calculated as

$$
f_{c}^{\Rightarrow}=f_{c}\left[1+a \sqrt{\frac{P}{f_{c}}}+b \frac{P}{f_{c}}\right],
$$

where $a$ and $b$ are changed as required. According to the balance of external and internal loads, the formula is presented as

$$
\begin{aligned}
N & =A_{c} \sigma_{c}+A_{s} \sigma_{1}, \\
\sigma_{2} t & =\frac{d_{c}}{2} p,
\end{aligned}
$$

where $N$ refers to the compressive strength, $A_{c}$ is the area of the core concrete, and $\sigma_{c}$ is the longitudinal stress of the core concrete. Furthermore, $A_{s}$ is the cross-sectional area of steel tube, $\sigma_{1}$ is the longitudinal stress of the steel tube, $\sigma_{2}$ refers to the radial tensile stress, $t$ is the thickness of the steel tube, and $d_{c}$ is the diameter of the core concrete. 

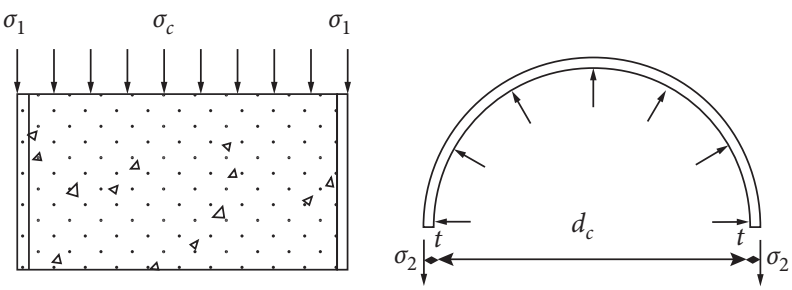

FIgURE 17: Internal force diagram of turntable structure.

Based on Von Mises conditions, the external steel tubes should satisfy

$$
\sigma_{1}^{2}+\sigma_{1} \sigma_{2}+\sigma_{2}^{2}=f_{s}^{2}
$$

Here, $\sigma_{c}$ can be calculated as

$$
\sigma_{c}=f_{c}\left[1+a \sqrt{\frac{P}{f_{c}}}+b \frac{P}{f_{c}}\right]
$$

Combined with (10)-(15), $\sigma_{1}$ can be obtained using

$$
\sigma_{1}=\sqrt{f_{s}^{2}-3 p^{2}\left(\frac{A_{s}}{A_{s}}\right)^{2}}-p \frac{A_{s}}{A_{s}}
$$

Alternatively, the formula can be stated as

$$
\sigma_{1}=\left[\sqrt{1-\frac{3}{\zeta^{2}}\left(\frac{p}{f_{c}}\right)^{2}}-\frac{1}{\zeta} \frac{p}{f_{c}}\right] f_{s},
$$

where $\zeta=A_{s} f_{s} / A_{c} f_{c}$ reflects the relationship between the external constraint and the core concrete, and it is called the confinement index, which can be obtained via this formula as $A_{s} f_{s} / A_{c} f_{c}$. Alternatively,

$$
\begin{aligned}
& p=\frac{2 t \sigma_{2}}{d_{c}}=\frac{1}{2} \frac{A_{s} \sigma_{2}}{A_{c}}, \\
& p=\frac{p_{\max }}{f_{c}}=\frac{1}{2} \frac{A_{s} f_{2}}{A_{c} f_{c}} .
\end{aligned}
$$

The above formula indicates that the ratio of the lateral pressure to the axial pressure is half of the confinement index. On combining (14) and (15) with (11), we get

$$
N=A_{c} f_{c}\left[1+\left(\sqrt{1-\frac{3}{\zeta^{2}\left(p / f_{c}\right)^{2}}}+\frac{a}{\zeta} \sqrt{\frac{p}{f_{c}}+\frac{b-1}{\zeta} \frac{p}{f_{c}}}\right) \zeta\right]
$$

According to (17), when the confinement index is a constant, the ultimate bearing capacity $N$ is a function of the lateral pressure $p$, and the derivative of $p$ is

$$
\frac{d N}{d p}=0
$$

Finally, we get

$$
\frac{3\left(p / f_{c}\right)}{\sqrt{\zeta^{2}-3\left(p / f_{c}\right)^{2}}}-\frac{a}{2 \sqrt{p / f_{c}}}-(b-1)=0 .
$$

The lateral pressure $p^{*}$ under the maximum load corresponding to the confinement index can be obtained from (19). According to (17), the bearing capacity of the compressive strength of the constrained turntable specimen is given as

$$
N=A_{c} f_{c}(1+\alpha \zeta)
$$

In (22), $\alpha$ can be attained by

$$
\begin{aligned}
& \frac{\sigma_{1}^{\Rightarrow}}{f_{s}}=\left[\sqrt{1-\frac{3}{\zeta^{2}\left(p / f_{c}\right)^{2}}}-\frac{1}{\zeta} \frac{p^{\Rightarrow}}{f_{c}}\right], \\
& \frac{\sigma_{1}^{\Rightarrow}}{f_{s}}=\left[\sqrt{1-\frac{3}{4\left(\sigma_{1}^{\Rightarrow} / f_{s}\right)^{2}}}-\frac{1}{\zeta} \frac{\sigma_{1}^{\Rightarrow}}{f_{c}}\right] .
\end{aligned}
$$

Because $P \Rightarrow / f_{c}=(1 / 2) A_{s} f_{s} / A_{c} f_{c}=(1 / 2) \zeta$, the formula can be written as

$$
\alpha=\frac{a}{\sqrt{2}} \frac{a}{\sqrt{\zeta}}+\left(b-\frac{1}{2}\right)
$$

Based on the above information, the formula to calculate the ultimate bearing capacity of compressive strength of steel tube-UHPC specimens is

$$
N=A_{c} f_{c}\left[1+\frac{a}{\sqrt{2}} \sqrt{\zeta}+(b-1) \zeta\right] .
$$

As per (26), the formula to obtain compressive bearing capacity of steel pipe UHPC spherical hinge is transformed into a formula related only to the confinement index $\zeta$ and parameters $a$ and $b$. The confinement index is related to the wall thickness of the steel pipe, and the parameters $a$ and $b$ can be fitted by the method of steel tube test and numerical analysis. 
We apply the finite element numerical analysis method to calculate the bearing capacity of the multiple sets of steel pipe UHPC specimens with different hoop coefficients. To model a steel tube, we need to consider the shaping effect of the material, i.e., the nonlinear effect of the material. During the analysis period, a classic bilinear follow-up hardening model is adopted: the stress-strain curve of the material contains two slope curves. The rising section is the elastic stage of the material, and its slope is the elastic modulus of the material; the straight line section is the deformation stage and its slope is 0 , where the material is in its reinforcement stage. The bilinear follow-up hardening model is simple and reliable, and it converges quickly during calculation. The constitutive relationship of the steel tube material is shown in Figure 18. The concrete material adopts a multilinear strengthening model. When the material arrives at the yielding stage, it enters the plastic stage. The yield strength increases with an increase in the load. The constitutive model of the concrete material is shown in Figure 19.

The models are created with SOLID65 units in ANASYS, and SOLID185 is used for the outer steel tubes; the steel tubes and core concrete are treated as contact units. The bottom is completely consolidated, and the top filled with core concrete is subjected to all pressures (Figure 20). In this test, the confining parameter of the steel tube-UHPC specimen is 0.2 . Therefore, 10 sets of confinement indices are selected to calculate the finite element model, as listed in Table 4.

The stress contours of finite element models of the seventh set are shown in Figure 21, and the crack development process is shown in Figures 22-24. According to the results of the stress contours, the compressive stress of the concrete in the spherical hinge is ring-shaped: the internal stress is low, and the compressive stress gradually increases with the increase in the radius. In the limit state, the core concrete compressive stress reaches $153 \mathrm{MPa}$, and the external steel pipe reaches $225 \mathrm{MPa}$. According to Figures 22-24, the specimens produce a crack along the outer edge of the spherical hinge under the 29th load step; at this time, the crack does not penetrate. At step 32, the cracks on the outer edge of the structure are connected as a whole and extend to the core concrete; however, all cracks are on the top surface, and the structure continues to bear the pressure. At step 73, the cracks propagate into the core concrete, all cracks penetrate up and down, and the structure reaches the failure stage. The model is consistent with the test results in terms of both the stress state and the failure mode, which proves that calculation results of the model are reliable.

The load value was considered as the value of the ultimate load; the load value is obtained when the core concrete reaches the ultimate strength or the external steel pipe reaches the yield strength. Based on the finite element results, (26) is fitted to calculate parameters $a$ and $b$.

As parameters $a$ and $b$ can be attained from Figure 25, the fitting formula is given as

$$
N=A_{c} f_{c}[1+1.658 \sqrt{\zeta}+4.874 \zeta] .
$$

Thus, when $a=2.87$, the standard deviation is 0.504 ; when $b=5.874$, the standard deviation is 0.86 . The value 0.982 is the curve fitness of the spherical hinge, which shows good agreement. The compressive strength of specimens in the fourth set can be obtained using (27) as the confinement index is $\zeta=\left(A_{s} f_{s} / A_{c} f_{c}\right)=0.2$ On substituting the confinement index into (26), the compressive strength of the specimens is obtained as $\sigma=N / A_{c}=206.2 \mathrm{MPaA}_{c}$, which is a deviation of $0.4 \%$ from the measured value of $207 \mathrm{MPa}$.

(3) Constrained by Stirrups.UHPC concrete features high compressive strength, good homogeneity, and small lateral deformation under vertical load; therefore, the mechanical properties of confined concrete compression structures with different strength levels and those with stirrups will be very different. In this case, their calculation model will be quite different from that of the traditional common reinforced concrete structures. The present paper then proposes a formula for calculating the strength of confined concrete in terms of stirrup-constrained spherical hinge; for example, the strength of the stirrups is related to diameter $d$ and distance $s$ of the stirrups. The area of the stirrups is converted to the equivalent thickness of the steel tube outside the spherical hinge for analysis, based on the principle of the equal area of the steel bar. The formula is given as

$$
f_{s d} A_{s}=f_{s} t s,
$$

where $f_{s d}$ is the tensile strength of the steel bar, $A_{s}$ is the cross-sectional area of the steel bar, $f_{s}$ is the equivalent steel tube tensile strength, and $t$ is the wall thickness of the equivalent steel tube. Assume $f_{s d}=f_{s}$; then, based on Figure 26, the balance formula is given as

$$
\sigma_{r}=\frac{2 t f_{s}}{R}
$$

where $\sigma_{r}$ refers to the peak stress of the core concrete. On combining (28) and (29), we get

$$
\sigma_{r}=\frac{2 t f_{s}}{R} * \frac{A_{s}}{s}
$$

The formula above shows that the peak stress of the core concrete is related to the equivalent hoop stress of the steel tube. According to Hooke's law, the lateral deformation of the material is related to the vertical deformation and Poisson's ratio. According to previous studies, when the core concrete reaches the peak stress, the formula to obtain axial strain of the core concrete is given by

$$
\varepsilon_{c c}=\varepsilon_{0}\left[1+26\left(k_{c}+\lambda_{t}\right)^{1,7}\right],
$$

where $\varepsilon_{0}=0.7 f_{\mathrm{co}}^{0,31} / 1000$ and the coefficient $\lambda_{t}=\rho_{v} f_{v} / f_{c o}$. Poisson's ratio in the limit state of concrete under the stirrup restraint is different from the value in the elastic stage. After testing multiple sets of specimens in the limit state [21, 22], Poisson's ratio is obtained, i.e., $v_{c c}=0.46$. In the limit state of the test piece-assuming the transverse 


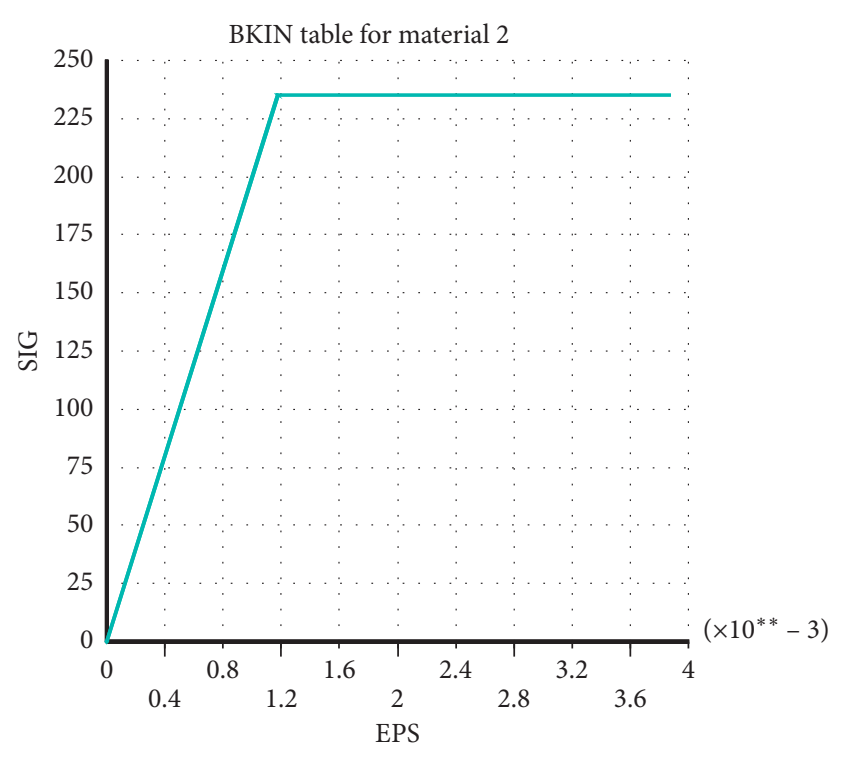

Figure 18: Constitutive model of steel tube.

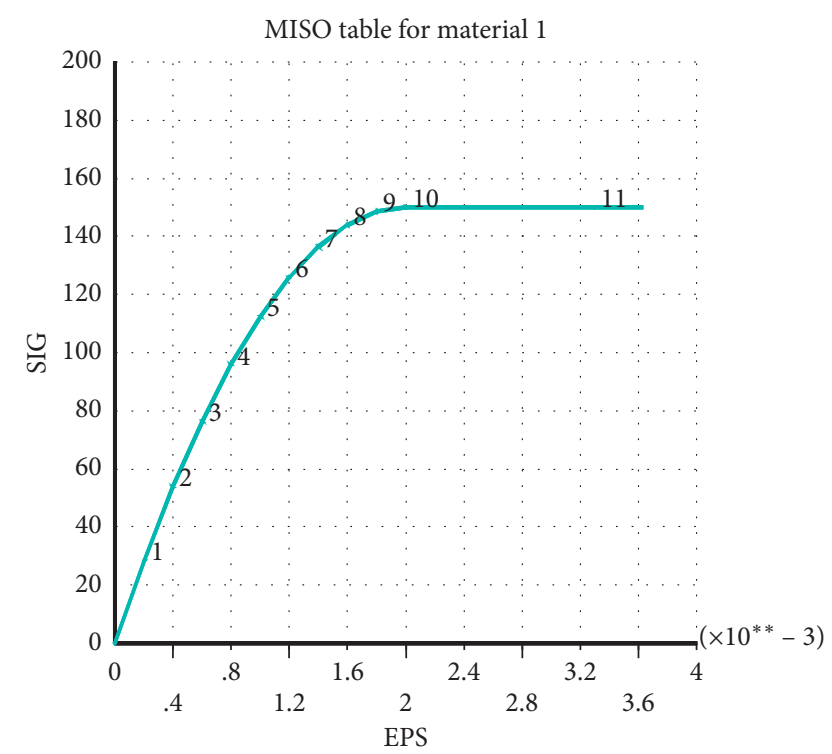

FIgURE 19: Constitutive model of steel concrete.

strain of the steel and concrete are the same-the equivalent circumferential stress of the steel pipe is

$$
f_{s}^{\prime}=\varepsilon_{c c} v_{c c} E_{s} .
$$

The constrained stress $\sigma_{r}$ under the ultimate state bearing capacity can be obtained by combining (32) and (30).

Previous studies $[21,22]$ have shown that there is a certain relationship between the compressive bearing capacity of constrained concrete and the constraining force $\sigma_{r}$. Thus, the formula to obtain the strength of the constrained concrete $f_{c c}$ is given as

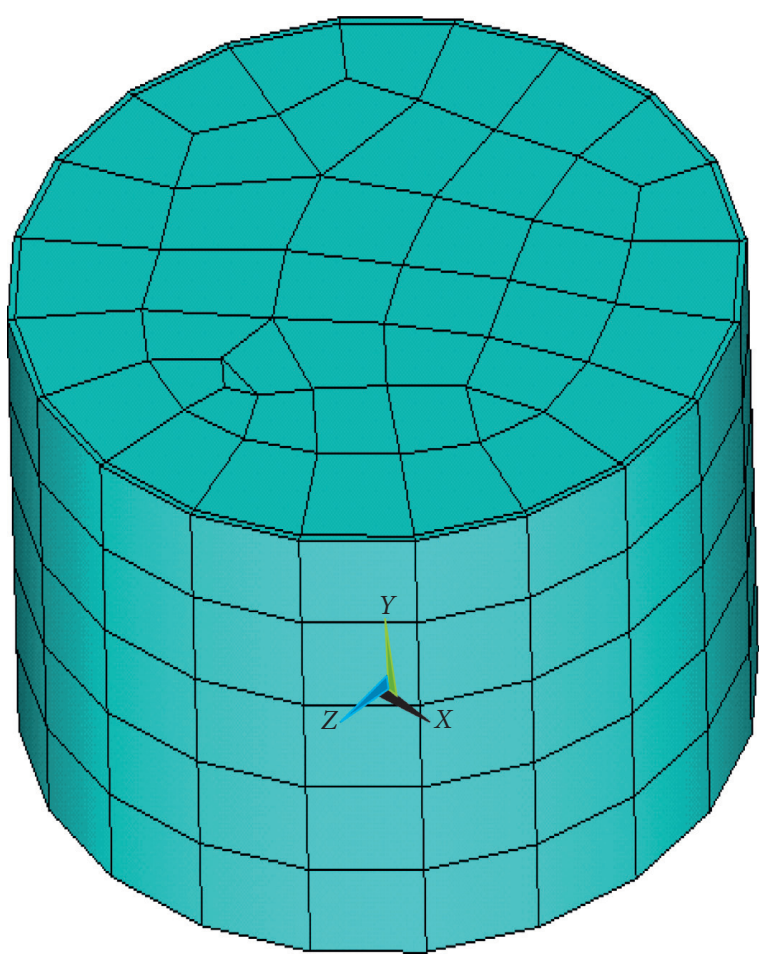

Figure 20: Finite element model mesh division.

$$
\frac{f_{c c}}{f_{c 0}}=085+a\left(\frac{\sigma_{r}^{\prime}}{f_{c o}}\right)^{b}
$$

where $f_{c c}$ is the compressive bearing capacity of the specimen constrained by stirrups. To obtain parameters $a$ and $b$, a large amount of test data is required for regression analysis. In this study, the compressive strength of 206 sets of stirrupconstrained specimens in the literature is used [21,22], and the values of the parameters $a$ and $b$ are fitted to 0.51 and 0.22 . The compressive strength of the stirrup-constrained spherical hinge specimen is given as

$$
f_{c c}=0.85 f_{c 0}+0.51 f_{c 0}\left(\frac{\sigma_{r}^{\prime}}{f_{c o}}\right)^{0.22} .
$$

According to (34), the compressive strength of the sixth set is $150 \mathrm{MPa}$. The deviation from the actual measured compressive strength is $9.8 \%$, which shows that the formula has a good fit.

(4) Directional Steel Fiber Spherical Hinge. The UHPC turntable specimens are divided into directional and randomly distributed ones. The presence of steel fibers contributes significantly to the improvement of the crack resistance of the material. When the steel fibers are aligned, the fiber arrangement direction is perpendicular to the cracking direction, which inhibits cracking to a certain extent and considerably improves the compressive strength of the turntable. Three theories are considered in terms of the enhancement influence of the steel fiber on the materials: composite mechanics theory, fiber cracking resistance 
TABLE 4: Compressive strength of test pieces with different confining parameters.

\begin{tabular}{lccc}
\hline $\begin{array}{l}\text { Finite element } \\
\text { number }\end{array}$ & Confinement index $\zeta$ & $\begin{array}{c}\text { Finite element model compressive strength } \\
(\mathrm{MPa})\end{array}$ & $\begin{array}{c}\text { Test results compressive strength } \\
(\mathrm{MPa})\end{array}$ \\
\hline 1 & 0 & 75.9 & $72.3(\mathrm{set} 1)$ \\
2 & 0.01 & 77.3 & $78(\mathrm{set} 5)$ \\
3 & 0.02 & 80.2 & $129.3(\mathrm{set} 6)$ \\
4 & 0.05 & 101.9 & \\
5 & 0.08 & 131.2 & $207(\mathrm{set})$ \\
6 & 0.1 & 158.2 & \\
7 & 0.2 & 208.3 & \\
8 & 0.3 & 256.2 & \\
9 & 0.4 & 291.2 & \\
10 & 0.5 & 320.2 & \\
\hline
\end{tabular}
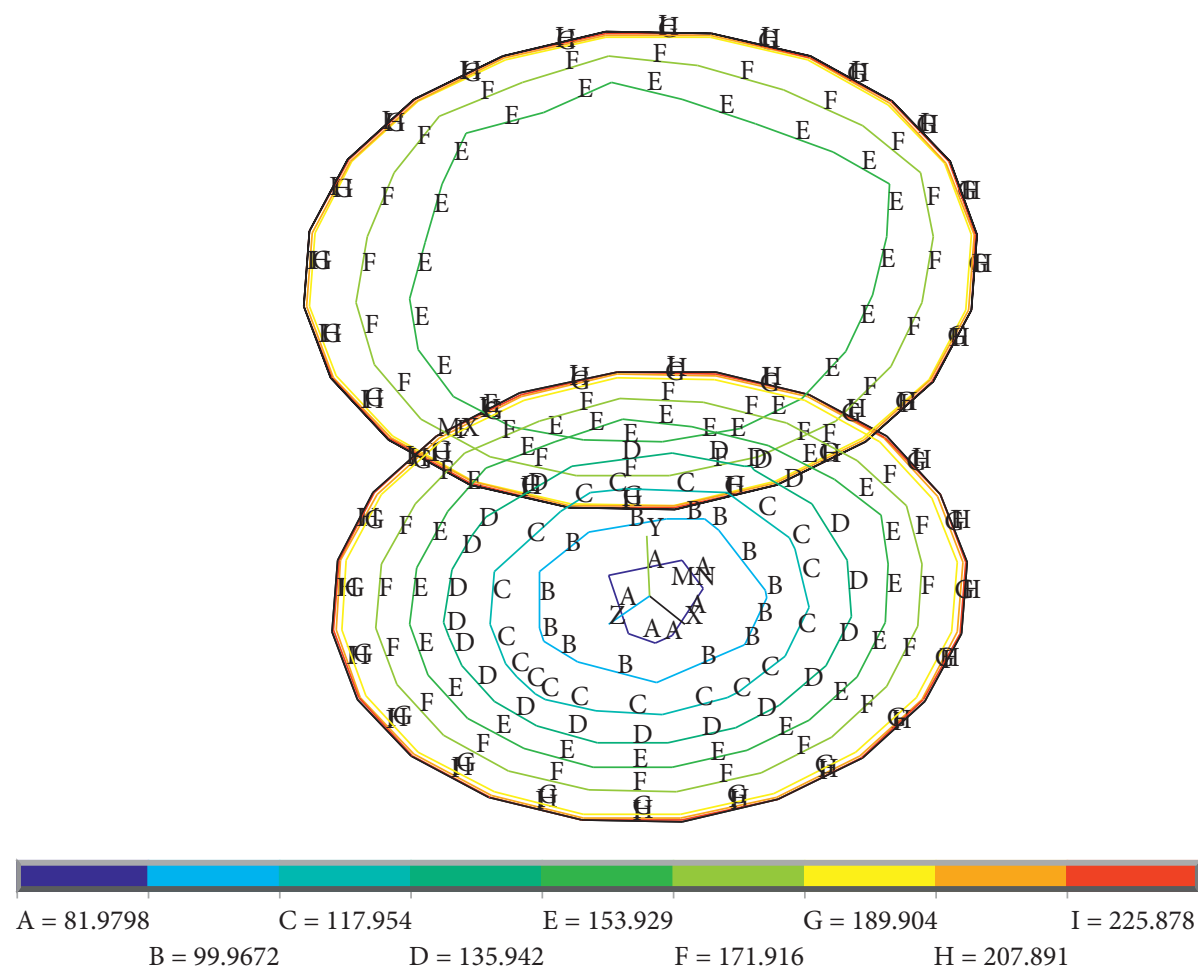

Figure 21: Model limit state stress diagram.

theory, and multislit cracking theory. For the directional steel fibers discussed in this section, it is assumed that the enhancement of the material is related to the direction coefficient and the distribution of steel fibers. This study investigates the advantages and disadvantages of the three methods, and it employs the fiber cracking theory to calculate the compressive strength of the specimens [23-26].

The fiber cracking theory is based on relevant theories of fracture mechanics for describing the restraint effect of steel fibers on cracks. There are natural holes and defects in UHPC concrete; hence, it is necessary to avoid the occurrence of internal stress concentration to reduce defects and improve the performance of materials. When a crack is generated inside the material and does not exceed the range of the steel fiber, it needs to span at least one steel fiber to exert an inhibitory effect on the crack and improve the crack resistance of the material. This theory assumes that the tensile stress of the fiber is uniformly distributed in the material with an average spacing of $S$ and a stress concentration coefficient $K_{1}$ generated at the crack end in the concrete. When the crack spreads to the cross section of the fiber and the material, shear stresses at the contact surface restrain the cracks. At this time, the crack tip generates a stress coefficient $K_{2}$, which is opposite to $K_{1}$, and the total stress concentration coefficient can be calculated via $K=K_{2}-K_{1}$. Romualdi proposed that the crack resistance of steel fibers is determined by their spacing. When the average spacing of steel fibers is less than $7.6 \mathrm{~mm}$, the material 


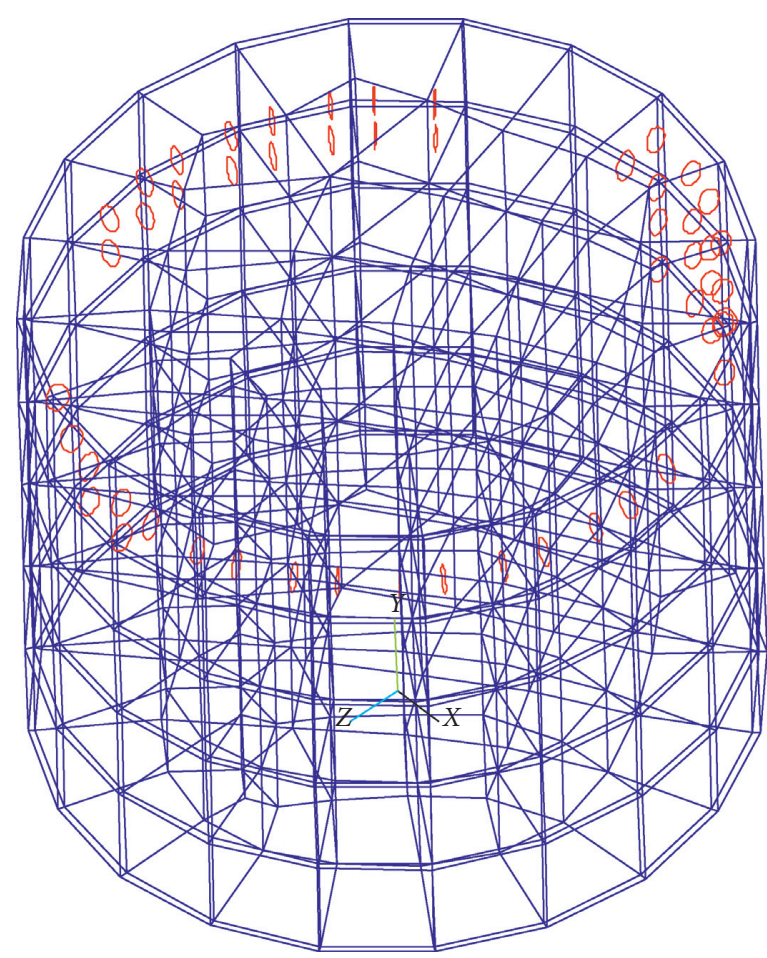

FIGURE 22: Spherical hinge cracking diagram 1.

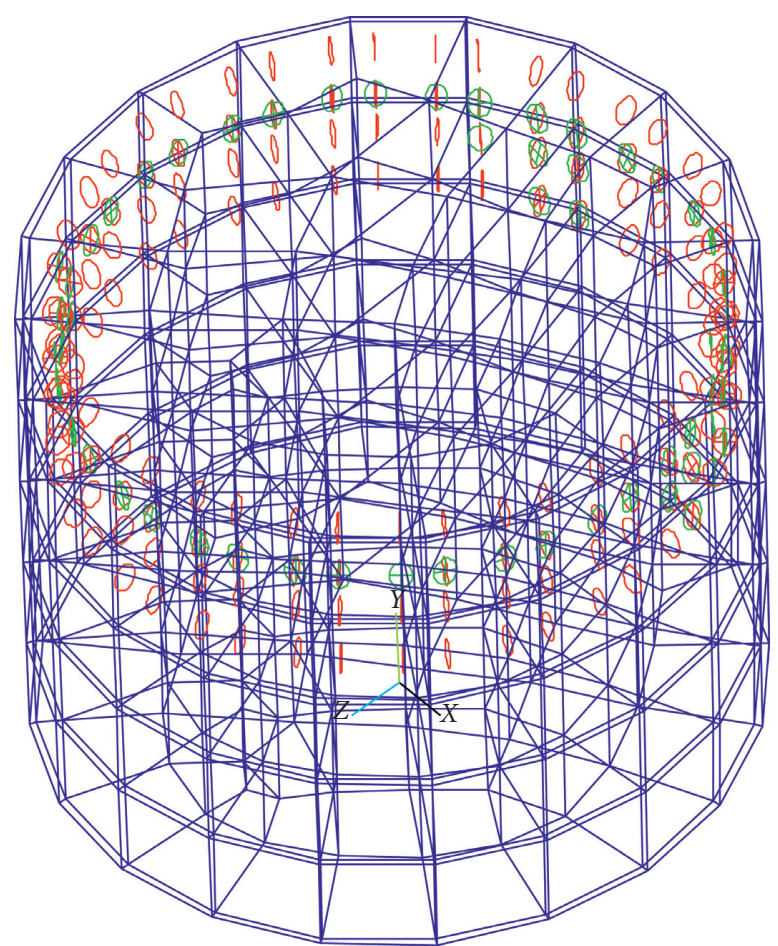

FIGURE 23: Spherical hinge cracking diagram 2.

properties can be improved considerably. When the fibers in the concrete are randomly distributed, the formula of the average distance $S$ is

$$
S=13.8 d \sqrt{\frac{1}{V_{b}}},
$$




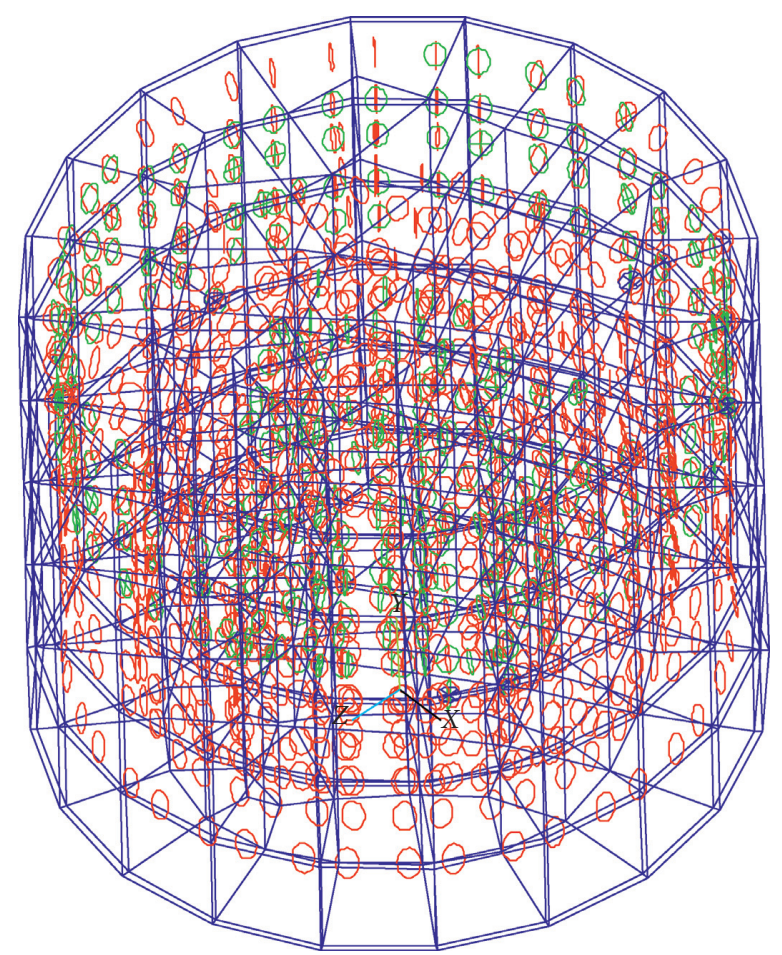

Figure 24: Spherical hinge cracking diagram 3.

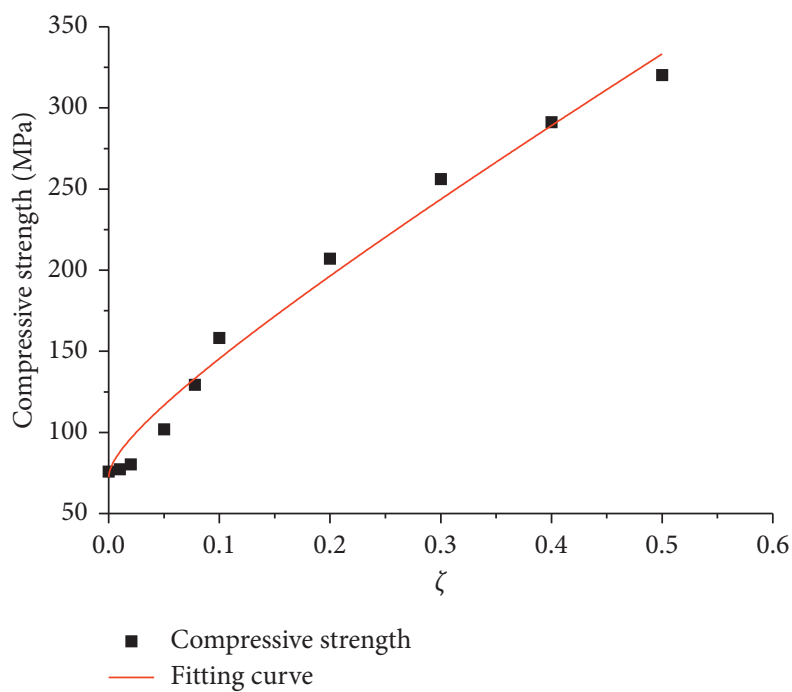

Figure 25: Fitting curve of compressive strength of CFST specimen.

where $d$ represents the diameter while $V_{b}$ is the content of the steel fibers.

Furthermore, Romualdi proposes models for the average spacing of fibers in different dimensions considering factors affecting the directions of steel fibers. When the fibers are one-dimensionally distributed, the direction coefficient is 1 and the formula is

$$
S=\frac{8.86 d}{\sqrt{V_{b}}} .
$$

When the fibers are two-dimensionally distributed, the direction coefficient is 0.64 , and the formula is given as

$$
S=\frac{11.1 d}{\sqrt{V_{b}}}
$$




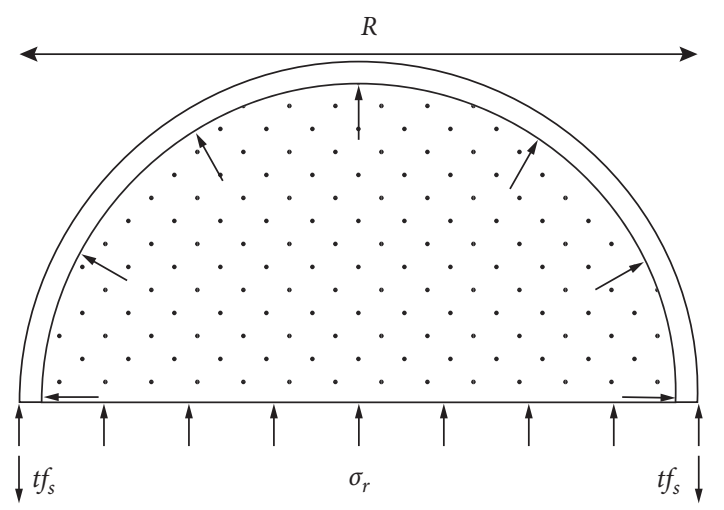

FIgURE 26: Internal force diagram of turntable structure.

When the fibers are three-dimensionally distributed, the direction coefficient is 0.41 , and the formula is given as

$$
S=\frac{13.8 d}{\sqrt{V_{b}}} .
$$

From the above formulas, it can be conjectured that the average spacing of steel fibers is related to the diameter and the content of the steel fibers; the larger the content, the smaller the average distance. Furthermore, the smaller the steel fiber diameter, the smaller the average spacing, and thus, the greater the constraint it will have on the cracks. The spacing of the three-dimensional constraint is greater than that of the one-dimensional one. In this study, the UHPC spherical hinge specimen with directionally arranged steel fibers can be regarded as a one-dimensional distribution. The UHPC spherical hinge specimens with randomly distributed steel fibers can be regarded as a three-dimensional distribution of the steel fibers. Furthermore, the average spacing of steel fiber specimens is 0.64 times than that of randomly distributed specimens, and its crack resistance is thus increased by $55.8 \%$. This is in line with the theory that claims cracks can be enhanced by the directional arrangement of steel fibers.

For the specimens in the first, second, and third sets, the compressive strength is related to the average distance of the steel fiber. According to (35), it is observed that the compressive strength of the specimen is proportional to the square root of the amount of the steel fiber. When the steel fiber amount is $2.5 \%$, its compressive strength would increase by about $20 \%$ and the compressive strength value should be $86 \mathrm{MPa}$. The actual test result is $83 \mathrm{MPa}$, which is $3.5 \%$ less than the theoretical value.

According to (36) and (37), the compressive strength is directly related to the orientation of the steel fibers. In the third set, the specimens are arranged in a certain direction to ensure its crack resistance at the maximum state. When steel fiber is set in one dimension, the average distance is $S=8.86 d / \sqrt{V_{b}}$. In the first set, the specimens with steel fibers are arranged in three dimensions, and the average distance is $S=13.8 d / \sqrt{V_{b}}$; thus, if the directional arrangement of the steel fiber samples increases by $55.8 \%$, the compressive strength is $112.7 \mathrm{MPa}$. The measured result is
$119 \mathrm{MPa}$, which is a deviation of $5.6 \%$. Therefore, after measuring the compressive strength of the spherical hinge, the compressive strength of the spherical hinge is preliminarily determined by the amount and arrangement direction of the steel fiber. However, the effect of the arranging direction of the steel fiber on the compressive strength of the spherical hinge needs to be studied further to obtain the precise relationship between the two.

\section{Conclusions}

In this study, we examined six sets of spherical hinge specimens using uniaxial compression tests, and we derived the compressive strength formula using the limit analysis theory. The following conclusions can be drawn:

(1) The compressive strength of the UHPC spherical hinge exceeded $72 \mathrm{MPa}$, thus meeting the requirements of 10,000 ton bridges during the rotation process. However, its safety factor does not meet the specification requirements, and hence, we do not recommend directly using UHPC spherical hinges in engineering applications.

(2) The compressive strength of the spherical hinge depends on the maximum radial compressive stress at the center of the sphere. When the radius of the spherical hinge was $100 \mathrm{~mm}$, the maximum compressive stress was 2.1 times the average compressive stress. The compressive stress distribution inside the specimen was uniform, and in this case, the compressive strength of the spherical hinge was less than that of the cube.

(3) The compressive strength of CFST spherical hinge turntable was $207 \mathrm{MPa}$, which meets the strength standard of Q235 steel spherical hinge of the same size. This serves as the experimental basis for replacing the traditional structure. The compressive strength formula was obtained by applying the limit analysis theory and finite element method.

(4) The compressive strength of the stirrup-constrained spherical hinge can be improved significantly; however, the restraining radius of the stirrup needs to be considered in the design. If this is not considered, the loading effect will be poor.

(5) The fiber cracking theory was employed to explain why the directional alignment of steel fibers can improve compressive strength. However, the size of the spherical hinge in this article is small, and the results are widely dispersed. The influence of the directional effect of steel fibers on compressive strength, further detailed experiments, and theoretical analysis are needed.

\section{Data Availability}

The data used to support the findings of this study are available from the corresponding author upon request. 


\section{Conflicts of Interest}

The authors declare that they have no conflicts of interest.

\section{References}

[1] M. Zuo and K. Jiang, "Study on the stress calculation method of the rotating pivot hinge in rotating body," Journal of Railway Standard Design, vol. 59, no. 12, pp. 36-39, 2015.

[2] J. He, "Analysis of mechanical characteristics of large span continuous bridge in rotation construction," Master's Degree Thesis vol. 32, no. 3, pp. 29-34, 2012.

[3] W. Feng, "Weighing test analysis of unbalanced body of Beijing Wuhuan road cable-stayed bridge," Railway Engineering, no. 4, pp. 4-6, 2005.

[4] P. Y. Blais and M. Couture, "Precast, prestressed pedestrian bridge World's first reactive powder concrete structure," $P C I$ Journal, vol. 44, no. 5, pp. 60-71, 1999.

[5] H. Liangqiu and F. Yang, "Application of RPC spherical hinge," Journal of Road Machinery and Construction Mechanization, vol. 35, no. 5, pp. 102-107, 2018.

[6] Z. Liu, "Effect of different amounts of silica fume on mechanical properties of reactive powder concrete," Journal of Commodity Concrete, vol. 30, no. 7, pp. 32-33, 2018.

[7] B. He, "Effect of water-cement ratio on the properties of RPC matrix," Science and Technology Innovation Herald, vol. 15, no. 10, pp. 92-94, 2018.

[8] T. Guo, T. Teng, and Q. Yu, "Effect of steel fiber content on strength and toughness of RPC under different curing conditions," Journal of Urban Housing, vol. 23, no. 8, pp. 119-121, 2016.

[9] S. Zhong, Concrete Filled Steel Tube Structure, Tsinghua University Press, Beijing, China, 2003.

[10] B. Chen, Research Progress and Engineering Application of Steel-Concrete Composite Structure Bridge in China, vol. 34, no. 1, Journal of Building Structures, pp. 5-6, 2013.

[11] J. Ma, "Stability of CFST flexural members and its application in Piers," Master Thesis of Nanjing University of Technology no. 3, pp. 2-12, 2009.

[12] R. Wang, X. Gao, Q. Li, and Y. Yang, "Influence of splitting load on transport properties of ultra-high performance concrete," Construction and Building Materials, vol. 171, no. 3, pp. 708-718, 2018.

[13] T. Chen, X. Gao, and M. Ren, "Effects of autoclave curing and fly ash on mechanical properties of ultra-high performance concrete," Construction and Building Materials, vol. 158, no. 3 , pp. 864-872, 2018.

[14] R. Wang, X. Gao, J. Zhang, and G. Han, "Spatial distribution of steel fibers and air bubbles in UHPC cylinder determined by X-ray CT method," Construction and Building Materials, vol. 160, no. 8, pp. 39-47, 2018.

[15] R. Wang, X. Gao, H. Huang, and G. Han, "Influence of rheological properties of cement mortar on steel fiber distribution in UHPC," Construction and Building Materials, vol. 144, no. 2, pp. 65-73, 2017.

[16] H. Huang, X. Gao, H. Wang, and H. Ye, "Influence of rice husk ash on strength and permeability of ultra-high performance concrete," Construction and Building Materials, vol. 149, no. 4, pp. 621-628, 2017.

[17] W. Jiawei and S. Quansheng, "Experimental research on compressive strength of UHPC spherical hinge," International Journal of Structural Integrity, vol. 11, no. 2, pp. 354378, 2019.
[18] ASTM C150/C150M, Standard Specification for Portland Cement, ASTM International, West Conshohocken, PA, USA, 2015.

[19] ASTM C1240-15, Standard Specification for Silica Fume Used in Cementitious Mixtures, ASTM International, West Conshohocken, PA, USA, 2015.

[20] S. Cao, "Finite element analysis of ultimate bearing capacity of RPC columns with round steel tubes under compression," Master's thesis of Beijing Jiaotong University vol. 32, no. 4, pp. 7-28, 2014.

[21] K. Yang and Q. Shi, "Study on constitutive model of high strength concrete confined by high strength stirrup," China Civil Engineering Journal, vol. 46, no. 1, pp. 35-39, 2013.

[22] Q. Shi and K. Yang, "Experimental study on mechanical behavior of high strength concrete confined by high-strength stirrups under concentric loading," Engineering Mechanics, vol. 29, no. 1, pp. 141-149, 2012.

[23] J. Jun, "Direction control and reinforcement effect of steel fiber in cement-based materials," Master's thesis of Hebei University of Technology vol. 43, no. 18, pp. 12-23, 2015.

[24] Li Yi and W. Zhao, Crack Resistance, Toughness and Durability of Complex Fiber Reinforced Concrete, Science Press, Beijing, China, 2012.

[25] X. Qiu, "Preparation technology and performance analysis of unidirectional steel fiber reinforced cement-based composite," Master's thesis of Hebei University of Technology vol. 38, no. 8, pp. 43-51, 2013.

[26] Q. Shi, "Experimental study of behavior on RPC filled steel tubular stub columns under axial compression," Engineering Mechanics, vol. 29, no. 9, pp. 141-142, 2012. 